\title{
BMJ Global Health Effective prevention of intimate partner violence through couples training: a randomised controlled trial of Indashyikirwa in Rwanda
}

\author{
Kristin Dunkle (D) , ${ }^{1}$ Erin Stern, ${ }^{2}$ Sangeeta Chatterji, ${ }^{3}$ Lori Heise ${ }^{3,4}$
}

To cite: Dunkle K, Stern E, Chatterii S, et al. Effective prevention of intimate partner violence through couples training: a randomised controlled trial of Indashyikirwa in Rwanda. BMJ Global Health 2020;5:e002439. doi:10.1136/ bmjgh-2020-002439

Handling editor Seye Abimbola

Received 26 February 2020

Revised 31 May 2020

Accepted 5 June 2020

A) Check for updates

C Author(s) (or their employer(s)) 2020. Re-use permitted under CC BY-NC. No commercial re-use. See rights and permissions. Published by BMJ.

${ }^{1}$ Gender and Health Research Unit, South African Medical Research Council, Tygerberg, Western Cape, South Africa ${ }^{2}$ Gender Violence and Health Centre, London School of Hygiene \& Tropical Medicine, Locon, UK

${ }^{3}$ Department of Population, Family and Reproductive Health, Johns Hopkins University Bloomberg School of Public Health, Baltimore, Maryland, USA

${ }^{4}$ Johns Hopkins University School of Nursing, Baltimore, Maryland, USA

Correspondence to Dr Kristin Dunkle; kdunkle@mrc.ac.za

\section{ABSTRACT}

Background Between 2015 and 2018, three civil society organisations in Rwanda implemented Indashyikirwa, a four-part intervention designed to reduce intimate partner violence (IPV) among couples and within communities. We assessed the impact of the programme's gender transformative curriculum for couples.

Methods Sectors $(\mathrm{n}=28)$ were purposively selected based on density of village savings and loan association (VLSA) groups and randomised (with stratification by district) to either the full community-level Indashyikirwa programme $(n=14)$ or VSLA-only control $(n=14)$. Within each sector, 60 couples recruited from VSLAs received either a 21-session curriculum or VSLA as usual. No blinding was attempted. Primary outcomes were perpetration (for men) or experience (for women) of past-year physical/sexual IPV at 24 months post-baseline, hypothesised to be reduced in intervention versus control (ClinicalTrials.gov: NCT03477877).

Results We enrolled 828 women and 821 men in the intervention sectors and 832 women and 830 men in the control sectors; at endline, 815 women $(98.4 \%)$ and 763 men $(92.9 \%)$ in the intervention and 802 women (96.4\%) and 773 men (93.1\%) were available for intention-to-treat analysis. Women in the intervention compared with control were less likely to report physical and/or sexual IPV at 24 months (adjusted relative risk (aRR) $=0.44,95 \% \mathrm{Cl} 0.34$ to 0.59 ). Men in the intervention compared with control were also significantly less likely to report perpetration of physical and/or sexual IPV at 24 months (aRR=0.54, $95 \% \mathrm{Cl} 0.38$ to 0.75 ). Additional intervention benefits included reductions in acceptability of wife beating, conflict with partner, depression, and corporal punishment against children and improved conflict management, communication, trust, self-efficacy, self-rated health, household earnings, food security and actions to prevent IPV. There were no study-related harms.

Conclusions The Indashyikirwa couples' training curriculum was highly effective in reducing IPV among male/female couples in rural Rwanda. Scale-up and adaptation to similar settings should be considered.

\section{INTRODUCTION}

Intimate partner violence (IPV) is the most common form of violence against women globally. ${ }^{1}$ It can lead to a wide range of

\section{Key questions}

\section{What is already known?}

- Intimate partner violence (IPV) is a serious health and human rights violation which impacts approximately one in three women worldwide.

- Women in many settings desire to keep their relationships intact while eliminating violence, but there is little evidence to date on how to do this safely and effectively.

\section{What are the new findings?}

- Couples who participated in the Indashyikirwa couples' training programme versus village savings and loan association (VSLA) alone had greatly reduced IPV at 24 months, with women $56 \%$ less likely to experience physical and/or sexual IPV and men $46 \%$ less likely to perpetrate physical and/or sexual IPV.

- Participants in the Indashyikirwa couples' training programme versus VSLA alone also experienced a range of other benefits including reduced conflict, better communication and trust, reduced exposure of children in the home to violence and improvements in health and household economic status.

\section{What do the new findings imply?}

- The Indashyikirwa couples' training programme was safe and highly effective at reducing IPV among male-female couples in rural Rwanda and brought a range of other related benefits to participating couples.

- Scale-up and adaptation of this evidence-based curriculum to similar settings should be considered.

negative health consequences including depression, anxiety, suicidal ideation, ${ }^{2}$ posttraumatic stress disorder (PTSD), ${ }^{3}$ drug and alcohol abuse, ${ }^{1}$ injuries and even death. In addition, IPV has been linked to poor sexual and reproductive outcomes, negative behavioural and health outcomes for children, and intergenerational patterns of abuse. ${ }^{4}$

A growing number of interventions to prevent or reduce IPV have been rigorously evaluated in sub-Saharan Africa, including 
programmes designed to empower women, engage men and boys, and transform community norms that condone violence and endorse male dominance. ${ }^{5}$ Several of these have demonstrated reductions in violence in the range of $30 \%-50 \%$ over 12-24 months of follow-up. ${ }^{6}$ Few programmes, however, have attempted to work directly with male-female couples to prevent and mitigate IPV, despite the fact that many such couples desire to stay together and/or women feel they have no viable economic or sociocultural alternative to leave.

Couple's programming around IPV raises valid concerns regarding safety, enforced reconciliation and implying mutual responsibility for violence among partners. ${ }^{8}$ Yet if managed responsibly, work with couples can avoid these pitfalls and potentially reduce the frequency and severity of abuse in relationships. In settings where half or more women experience some form of violence, and both women and men may view physical discipline and non-consensual sex as a husband's prerogative, women need viable options for addressing violence in their relationships beyond leaving, ${ }^{9}$ especially in settings where male partners offer critical economic support and social norms provide little to no support for ending a partnership. Challenging harmful gender norms, addressing relationship dynamics and teaching both partners skills in self-regulation, communication and managing conflict can help women feel safer within relationships that they otherwise value. $^{810}$

There is thus emerging interest in working with couples on IPV prevention, especially in the Global South. ${ }^{11}$ Such approaches typically use group or community-based formats with trained facilitators rather than therapists or counsellors, and often respond to high generalised rates of IPV, as well as economic and social conditions that hinder women from leaving unsafe relationships. ${ }^{12}$ This paper seeks to enhance the global evidence base on couples' programming by sharing findings from an evaluation of the couples' component of Indashyikirwa, an IPV prevention programme in Rwanda. A separate manuscript presents findings from the results from repeat cross-sectional surveys of the communities before and after the three other components of Indashyikirwa, as well as insights from the detailed process evaluation that accompanied the rollout. ${ }^{13}$

The full Indashyikirwa 'Agents of Change' programme included four interlocking components: a 21-session couples' curriculum; community outreach by trained community activists; the creation of an enabling environment through training and active involvement of key opinion leaders; and provision of support to victims through the creation of women's 'safe spaces'. ${ }^{13} 14$ The Couples Curriculum drew on Journeys of Transformation (JoT) - a 17-session participatory curriculum implemented by CARE Rwanda, the Rwandan Men's Resource Centre (RWAMREC) and Promundo-to foster men's support of their partners' participation in CARE's village savings and loan associations (VSLA). A small mixedmethod evaluation found that the JoT curriculum reduced household-level poverty and had a positive impact on partners' collaboration around household and care work, family relations and decision-making, but had an unclear impact on IPV. ${ }^{15}$ As part of explicitly addressing IPV prevention, Indashyikirwa also drew heavily from SASA!, a community mobilisation programme implemented by CEDOVIP (Centre for Domestic Violence Prevention) and Raising Voices in Kampala, Uganda. A randomised controlled trial of SASA! found significant shifts in acceptance of IPV, and a 52\% reduction in past-year reports of physical IPV among women experiencing violence at baseline. ${ }^{76-18}$ In this study, graduates of the couples' training curriculum who wished to carry the work forward to others were offered the opportunity to put themselves forward for additional training as community activists, to help facilitate a broader process of community change. While only about $25 \%$ of the couples' training graduates received this additional training due to budgetary constraints, many more individuals engaged in community education and advocacy activities either in support of their partners who had been so trained or at their own initiative. Findings from this aspect of Indashyikirwa are described in detail elsewhere. ${ }^{13}$

To assess the impact of the Indashyikirwa couples' programme, we conducted a community randomised controlled trial (cRCT). Outcomes for participants in the couples' training were assessed at the individual level. We hypothesised that participation in the couples training, in the context of the broader Indashyikirwa programme, would lead to reduced experience of IPV among women and reduced perpetration of IPV among men, accompanied by reductions in the number of children witnessing IPV and increased help seeking among women experiencing IPV. We additionally hypothesised that couples participating in the training would experience improved relationship quality, reduced depression, reduced alcohol use (for men only), reduced belief in the acceptability of IPV and increased engagement with their communities around IPV. At the request of implementing partners, we also specified exploratory outcomes related to the possible beneficial impact of the programme on household economic status, parenting practices and participants' health.

\section{METHODS \\ Study location, design and community randomisation}

The Indashyikirwa trial was implemented in seven districts of Rwanda, spread across the Eastern, Northern and Western provinces. Implementation districts were chosen by the programme implementing partners based on examination of the RDHS 2010 data to identify areas with high rates of IPV, in combination with a strong presence of CARE's VSLA programmes. ${ }^{19}$ Because the full fourcomponent Indashyikirwa programme was designed to operate at sector level, sectors were chosen as the unit of randomisation for the impact evaluation. To identify potential sectors for inclusion in the cRCT, we mapped 


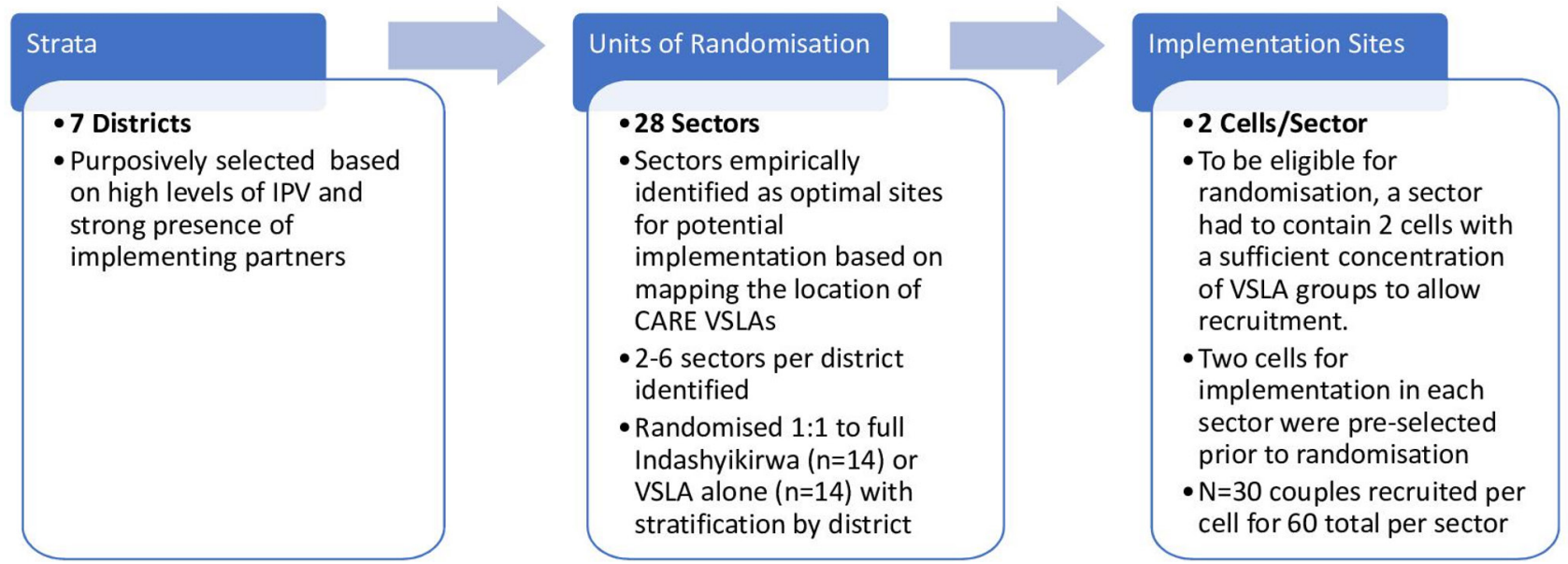

Figure 1 Geographic organisation of the trial and implementation sites. IPV, intimate partner violence; VLSA, village savings and loan association.

GPS (Global Positioning System) coordinates of the meeting locations for active VSLA groups to identify those sectors with a sufficient concentration of VSLAs to support implementation of two distinct Couples' groups in different cells within the sector (figure 1). Sectors identified as having adequate recruitment potential were then reviewed with programme partners to ensure that each identified sector could be equally viable as either an intervention or control area. As part of this eligibility assessment, two cells within that sectors were preselected as sites for implementation of either couples' curriculum or control group recruitment. The top 28 sectors thus identified were then randomised by an independent statistician, with stratification across the seven districts. The final number of sectors per district ranged from 2 to 6 . Due to the need to obtain approval from district and sector-level gatekeepers before enrolling participants, no blinding of participants, enumerators or other study staff was attempted. Gatekeeper approval was obtained by RWAMREC staff for intervention sites, and for control sites, it was handled in partnership by RWAMREC and senior field staff employed by Laterite Ltd., the local research firm contracted for data collection.

\section{Identification and selection of participants}

RWAMREC staff handled recruitment of potential intervention participants in the intervention sectors, while recruitment for control participants was conducted by field staff employed by Laterite. In both cases, the eligibility criteria for couples to enrol were as follows: at least one member of the couple had to be an active VSLA member; they must live together or be married to each other for at least 6 months prior to enrolment; both partners should be between 18 and 49 years old; and they should have no current plans to move out of the cluster in the next 2.5 years.

To recruit intervention participants, RWAMREC invited all VSLA members (the majority of whom are women) in each of the two preselected cells per sector to a community meeting where they announced the forthcoming programme and invited those in potentially eligible couples to put themselves forward for participation. Participants were then randomly selected by public lottery from among those eligible couples who volunteered. Participation in the impact evaluation was not mandatory for individuals to participate in the couples training, but all participants who signed up for the trainings were invited to participate in the impact evaluations. In the control communities, field staff from Laterite invited all VSLA members in each of the two identified cells to a similar community meeting to describe the research and invited eligible couples to volunteer to participate in a series of three interviews over a period of 24 months. A random lottery was again conducted from among the volunteers to select final participants.

The full four-component Indashyikirwa programme was implemented in all intervention sectors by CARE Rwanda, RWAMREC and the Rwanda Women's Network (RWN). The Couple's Curriculum incorporated the $S A S A$ ! programme's emphasis on positive and negative types and uses of power, critical personal reflection and positive aspirations for healthy relationships. ${ }^{7} 1820$ The curriculum also worked explicitly to address triggers of IPV (including disagreements about money, jealousy and alcohol abuse) and emphasised skills building to create positive alternatives to violence. ${ }^{21}$ The full training manual is available online (https://www.whatworks.co. $\mathrm{za} /$ resources/item/560-couples-curriculum-trainingmodule) and training manuals for the other three components are available on the website (https://www. whatworks.co.za/). The control sectors continued routine implementation of CARE-run VSLA programmes.

\section{Data collection procedures}

Data were collected at baseline, 12 months post-baseline and 24 months post-baseline. For the baseline round of data collection, all potential participants identified during recruitment were invited to attend appointments at a convenient central location, with separate data collection locations for women and men. For follow-up 
interviews, field staff phoned ahead to verify participants' current locations and set up appointments for interviews. By default, all interviews were conducted in Kinyarwanda via ACASI (audio-enhanced computer self-interviewing). Gender-matched interviewers stayed close at hand to assist participants who required clarifications or technical assistance. Participants who were not sufficiently literate to make use of the technology or who for any reason preferred an in-person interview were interviewed faceto-face by a gender-matched enumerator. This option was chosen by $23.8 \% \quad(n=395)$ of women and $14.6 \%(n=240)$ of men at baseline; $25.8 \%(n=423)$ of women and $9.5 \%$ $(\mathrm{n}=151)$ of men at 12 months follow-up; and $18.9 \%$ $(n=306)$ of women and $5.9 \%(n=90)$ of men at endline.

\section{Outcomes}

Table 1 describes the primary, secondary and exploratory outcome measures included for women and men. The primary outcome was experience (for women) or perpetration (for men) of physical and/or sexual IPV in the previous 12 months assessed using the adapted WHO violence against women tools. ${ }^{22}$ It included five items on physical IPV and three items on sexual IPV with answer choices of never, once, a few times or many times. Per the What Works consortium agreement on IPV primary outcome measure, it was coded as 'yes' if any answer was >once and/or multiple items were endorsed. To further examine how the intervention impacted on IPV, we also defined a small number of secondary outcomes related to IPV. These included looking at subgroup analysis among those who did and did not report experience of the primary IPV outcome at baseline (to look at primary prevention vs cessation of IPV), and separate analysis of the four individual types of IPV: physical IPV, forced or coerced sex (sexual IPV), economic abuse and (women's report only) emotional aggression/abuse.

\section{Sample size}

The number of couples to be trained using the Indashyikirwa curriculum was set by the implementing partners based on operational and budgeting constraints. We thus had a fixed number of sectors $(\mathrm{n}=28 ; 14$ intervention and 14 control) as well as a fixed cluster size within each sector (60 couples). From these fixed numbers, we calculated the minimum detectable difference given $\alpha=0.05$ and $\beta=0.80$, and allowing for up to $20 \%$ loss to follow-up using equation 26 in Hemming et al. ${ }^{23}$ We used intracluster correlation coefficients (ICCs) estimated conservatively at 0.20 as well as a more typical ICC $=0.10$ and estimated the detectable reduction in past 12 months IPV for baseline prevalence ranging from $10 \%$ to $30 \%$. These estimates allow for a relative detectable difference of $44 \%-26 \%$ (detectable absolute difference of $9.3 \%-4.4 \%$ ) which was considered adequate power, as best evidence interventions for IPV prevention tend to show relative reductions of around $30 \%-50 \% .^{616}$

\section{Data analysis}

All participants were used in the data analysis, excluding those who were only present at baseline. We first described baseline characteristics of men and women across study arms. Because of the cluster-level randomisation, lack of masking and slight differences in recruitment procedures across study arms, we tested for differences between intervention and control participants and adjusted subsequent analysis for variables found to be significantly different between arms. We then checked if there was any differential loss to follow-up by study arm assignment or baseline demographic characteristics and included these as baseline covariates in outcome models. All tests took into account the complex sampling nature of the data, treating sectors as cluster and districts as sampling strata in computation of standard errors.

To evaluate the impact of the intervention at the 24-month follow-up, we performed an intention-to-treat (ITT) analysis using generalised linear mixed effects modelling (multilevel model for change) with a Gaussian link function to compare mean scores at endline for all continuous outcomes and a Poisson link function for count data. ${ }^{24}$ For the binary outcomes, we used generalised linear mixed effects models with a logit link function to compare the effect of the intervention between the two study arms. The fixed effects terms in all models included the study arm, data collection wave and an interaction term for study arm and data collection wave. The district in which data were collected was also treated as a fixed effect to account for possible geographic variation in impact. Sector (the unit of randomisation) was added in as a random effects term. Based on the findings regarding demographics and loss to follow-up, models for outcomes among women were adjusted for type of VSLA membership reported at baseline (self, partner or both); baseline asset scores; and experience of physical or sexual IPV from a previous partner. For men, covariates for outcomes models were marriage versus cohabitation at baseline, VSLA membership type, baseline asset scores and being beaten often or very often as a child. All models were adjusted for age and the baseline value of the outcome in question.

The effect of the intervention was assessed at 12 and 24 months (endline) using linear combinations of the fixed effect terms in the model (study arm and data collection wave). The 12-month findings are considered as interim results and the 24-month findings are considered the final effects. We compared women from the control arm with women from the intervention arm, and men from the control arm with men from the intervention arm. Stata/SE V.16.0 was used for final data analysis.

\section{Ethics}

All participants provided written informed consent; illiterate participants could opt to have the form read to them by study personnel or a trusted person of their choosing. A female professional counsellor, organised by the study, was available to support participants who 
Table 1 Measurement of registered outcomes for the Indashyikirwa couples' cohort

\begin{tabular}{|c|c|c|c|c|c|}
\hline Women & Men & How assessed & $\begin{array}{l}\text { Items, } \\
\mathrm{n}\end{array}$ & $\begin{array}{l}\text { Method of } \\
\text { scaling }\end{array}$ & $\begin{array}{l}\text { Hypothesised } \\
\text { direction }\end{array}$ \\
\hline \multicolumn{6}{|l|}{ Primary outcome } \\
\hline $\begin{array}{l}\text { Experience of physical or sexual } \\
\text { IPV in the past } 12 \text { months from } \\
\text { current male partner, assessed using } \\
\text { standardised What Works consortium } \\
\text { definition }\end{array}$ & $\begin{array}{l}\text { Experience of physical or sexual IPV in } \\
\text { the past } 12 \text { months from current male } \\
\text { partner, assessed using standardised } \\
\text { What Works consortium definition }\end{array}$ & $\begin{array}{l}\text { Adapted WHO violence against women } \\
\text { instrument; five items on physical IPV, three items } \\
\text { on sexual IPV, covering past } 12 \text { months. Answer } \\
\text { choices: never, once, a few times, many times. } \\
\text { Coded as 'yes' per What Works definition if any } \\
\text { answer >once and/or multiple items endorsed. }\end{array}$ & 8 & Binary & Reduced \\
\hline
\end{tabular}

Secondary outcomes

$\underline{I P V-r e l a t e d ~ s e c o n d a r y ~ o u t c o m e s ~}$

\section{By experience of IPV reported at}

baseline

IPV among women reporting no experience of IPV (What Works definition) in the past year at baseline

\begin{tabular}{|c|c|c|c|c|c|}
\hline $\begin{array}{l}\text { IPV among women who did } \\
\text { experience IPV (What Works } \\
\text { definition) in the past year at baseline }\end{array}$ & $\begin{array}{l}\text { IPV among men who did report IPV } \\
\text { perpetration (What Works definition) in } \\
\text { the past year at baseline }\end{array}$ & As above & 8 & Binary & Reduced \\
\hline
\end{tabular}

By specific type of IPV

\begin{tabular}{|c|c|c|c|c|c|}
\hline $\begin{array}{l}\text { Any experience of physical IPV } \\
\text { from the main partner in the past } 12 \\
\text { months }\end{array}$ & $\begin{array}{l}\text { Any physical IPV used in main } \\
\text { partnership in the past } 12 \text { months }\end{array}$ & $\begin{array}{l}\text { Any affirmative response on any of the physical } \\
\text { IPV items }\end{array}$ & 5 & Binary & Reduced \\
\hline $\begin{array}{l}\text { Any forced or coerced sex with main } \\
\text { partner in the past } 12 \text { months }\end{array}$ & $\begin{array}{l}\text { Any forced or coerced sex with main } \\
\text { partner in the past } 12 \text { months }\end{array}$ & $\begin{array}{l}\text { Any affirmative response on any of the items } \\
\text { on forced or coerced sex (sexual IPV) with main } \\
\text { partner }\end{array}$ & 3 & Binary & Reduced \\
\hline $\begin{array}{l}\text { Any experience of economic abuse } \\
\text { by the main partner in the past } 12 \\
\text { months }\end{array}$ & $\begin{array}{l}\text { Any economic abuse with main partner } \\
\text { in the past } 12 \text { months }\end{array}$ & $\begin{array}{l}\text { Any affirmative response on any of the items on } \\
\text { economic abuse with main partner }\end{array}$ & 3 & Binary & Reduced \\
\hline $\begin{array}{l}\text { Any experience of emotional } \\
\text { aggression/abuse from main partner } \\
\text { in the past } 12 \text { months }\end{array}$ & Not assessed & $\begin{array}{l}\text { Any affirmative response on any of the items on } \\
\text { emotional abuse from main partner }\end{array}$ & 4 & Binary & Reduced \\
\hline \multicolumn{6}{|l|}{ Children in household witnessing IPV } \\
\hline $\begin{array}{l}\text { Children in household witnessing } \\
\text { IPV (taken out of all households with } \\
\text { children and physical or sexual IPV in } \\
\text { the last } 12 \text { months at each wave) }\end{array}$ & Not assessed & $\begin{array}{l}\text { Mother's reports of frequency of children } \\
\text { witnessing violence against their mother }\end{array}$ & 1 & Binary & Reduced \\
\hline \multicolumn{6}{|l|}{ Help seeking } \\
\hline $\begin{array}{l}\text { Help seeking among survivors of IPV } \\
\text { (taken out of women reporting any } \\
\text { physical or sexual IPV in the last } 12 \\
\text { months at each wave) }\end{array}$ & Not assessed & $\begin{array}{l}\text { Thinking now only about the PAST YEAR, how } \\
\text { often have you asked anyone for help or advice } \\
\text { related to your husband's violence? Coded as } \\
\text { any requests for help. }\end{array}$ & 1 & Binary & Increase \\
\hline
\end{tabular}

\section{Relationship quality}

Level of conflict in intimate partnership

Level of conflict in intimate partnership

\section{(Pos} "In the past 12 months, how often have you and
your husband quarrelled about his drinking?"
(Possible range 0-24; lower scores represent better outcomes)

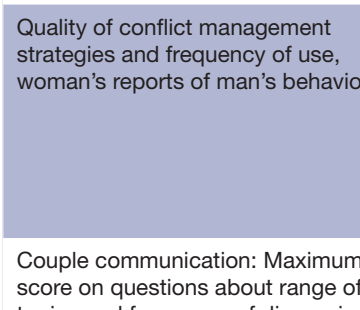

score on questions about range of
Perception of trust, care and respect
in relationship with main partner: Maximum score
Quality of conflict management strategies and frequency of use, selfreports of behaviour
Couple communication: Maximum score on questions about range of topics and frequency of discussion
Frequency of different responses to conflict. Reverse coded for negative strategies. Typical item: "In the past 12 months, when you and your partner have argued, you expressed how you felt in a calm and respectful way. 1 . Never 2. Once 3. A few times 4. Many times" (Possible range 6-24, higher scores represent better outcomes)

Frequency of discussing different topics in past 4 weeks. Typical item, "During the last 4 weeks how often did you and your husband discuss your worries or feelings?" (Possible range was 5-20 points, but over $20 \%$ of participants scored 20 at baseline, so the measure was dichotomised)

Perception of trust, care and respect in relationship with main partner: Maximum score

\section{Feeling cared for, feeling respected, trust in} partner, partner trust in respondent. Typical item, "In the past 12 months, have you felt respected by your wife: 1 . Always 2 . Sometimes 3 . Never?" (Possible range was 4-14 points, but over 30\% of participants scored 14 at baseline, so the measure was dichotomised)
Mean score Reduced (Cronbach's alpha for

scale: 0.78 for women, 0.80 for men)

Mean score Increase (Cronbach's alpha for scale: 0.49 for women, 0.60 for men)

Binary (coded Increase 1 for achieving max score, 0 otherwise)

Binary (coded Increase

1 for achieving max score, 0 otherwise) 
BMJ Global Health

Table 1 Continued

\begin{tabular}{llll}
\hline Women & Men & How assessed & $\begin{array}{l}\text { Hypothesised } \\
\text { direction }\end{array}$
\end{tabular}

Beliefs and community engagement

\begin{tabular}{|c|c|c|c|c|}
\hline Acceptability of wife beating & Acceptability of wife beating & $\begin{array}{l}\text { Questions from Rwanda Demographic and Health } \\
\text { Survey. Scored on four-point Likert scale. Typical } \\
\text { item, "A man has a good reason to hit his wife if } \\
\text { he suspects she has been unfaithful in marriage." } \\
\text { (Number of reasons endorsed as justifications, } \\
\text { range 0-5) }\end{array}$ & $\begin{array}{l}\text { Mean score. } \\
\text { Coded as } \\
1 \text { point for } \\
\text { each "Agree" } \\
\text { or "Strongly } \\
\text { Agree" }\end{array}$ & Reduced \\
\hline $\begin{array}{l}\text { Self-efficacy for community } \\
\text { engagement }\end{array}$ & Not assessed & $\begin{array}{l}\text { "How confident are you that you could express } \\
\text { your opinion at a community meeting?" and "How }\end{array}$ & $\begin{array}{l}\text { Mean total } \\
\text { score }\end{array}$ & Increase \\
\hline
\end{tabular}

confident are you that you could express your

opinion at a community meeting if some people

did not agree with you?" Answer choices: 1.

Very confident; 2 . Somewhat confident; 3 . Not

confident at all (code reversed for analysis; final

possible range 2-6 where higher scores represent

better outcomes)

\begin{tabular}{|c|c|c|c|c|c|}
\hline Not assessed & $\begin{array}{l}\text { Feels confident advising neighbours } \\
\text { on relationships }\end{array}$ & $\begin{array}{l}\text { Neighbours often have similar problems (eg, } \\
\text { around raising children, family violence). How } \\
\text { confident do you feel about offering advice } \\
\text { to a neighbour or friend? } 1 \text {. Very confident; } 2 \text {. } \\
\text { Confident but would need to be encouraged; } 3 \text {. } \\
\text { Not confident at all; } 4 \text {. Don't know }\end{array}$ & 1 & $\begin{array}{l}\text { Binary (coded } \\
1 \text { for 'very } \\
\text { confident', } 0 \\
\text { otherwise) }\end{array}$ & Increase \\
\hline Not assessed & $\begin{array}{l}\text { Has advised neighbours on } \\
\text { relationships in past } 12 \text { months }\end{array}$ & $\begin{array}{l}\text { Have you offered such advice in the last } 12 \\
\text { months? } 1 . \text { Never; } 2 \text {. Once; } 3 \text {. Twice; } 4.3 \text { or more } \\
\text { times }\end{array}$ & 1 & $\begin{array}{l}\text { Binary (coded } \\
\text { one for 'three } \\
\text { or more times', } \\
0 \text { otherwise) }\end{array}$ & Increase \\
\hline Participating in action to prevent IPV & Participating in action to prevent IPV & $\begin{array}{l}\text { In the past } 12 \text { months, have you participated in a } \\
\text { meeting, march, rally or gathering aiming to raise } \\
\text { awareness and mobilise people around the issue } \\
\text { of family violence? Yes/ No }\end{array}$ & 1 & Binary & Increase \\
\hline \multicolumn{6}{|l|}{ Mental Health } \\
\hline Depressive symptoms & Depressive symptom & $\begin{array}{l}\text { Assessed using the Centre for Epidemiologic } \\
\text { Studies-Depression (CES-D) } 10 .{ }^{42} \text { Typical item, } \\
\text { "During the past week, I felt that everything I did } \\
\text { was an effort." (Possible range } 0-18 \text { ) }\end{array}$ & 10 & $\begin{array}{l}\text { Mean score } \\
\text { (Cronbach's } \\
\text { alpha for } \\
\text { scale: } 0.76 \text { for } \\
\text { women, } 0.71 \\
\text { for men) }\end{array}$ & Reduced \\
\hline See exploratory outcomes & Problematic alcohol use & $\begin{array}{l}\text { Alcohol Use Disorder Identification Test- } \\
\text { Consumption (AUDIT-C). }{ }^{43} 44 \text { Scores of } 0 \text { assigned } \\
\text { to non-drinkers. Assessed for men at all time } \\
\text { points; added for women at midline and endline } \\
\text { only. (possible range } 0-12 \text { ) }\end{array}$ & 3 & $\begin{array}{l}\text { Binary (coded } \\
1 \text { for score of } \\
4 \text { or higher, } \\
0 \text { otherwise } \\
\text { and for non- } \\
\text { drinkers) }\end{array}$ & Reduced \\
\hline
\end{tabular}

Exploratory outcomes

Economic outcomes, past month

\begin{tabular}{|c|c|c|c|c|c|}
\hline Any earned income & Any earned income & $\begin{array}{l}\text { Considering all the money you earned from jobs } \\
\text { or selling things, how much did you earn in the } \\
\text { LAST MONTH? }\end{array}$ & 1 & $\begin{array}{l}\text { Binary (coded } \\
1 \text { for any } \\
\text { answer }>0 ; 0 \\
\text { otherwise) }\end{array}$ & Increase \\
\hline Any household debt payments & Any household debt payments & $\begin{array}{l}\text { How much did you or any other members of your } \\
\text { household have to pay in debt last month? }\end{array}$ & 1 & $\begin{array}{l}\text { Binary (coded } \\
1 \text { for any } \\
\text { answer }>0 ; 0 \\
\text { otherwise) }\end{array}$ & Reduced \\
\hline Food security & Food security & Score of 0 on hunger questions below & 2 & $\begin{array}{l}\text { Binary (coded } \\
1 \text { for score } \\
\text { of } 0 \text { on both } \\
\text { hunger } \\
\text { questions; } 0 \\
\text { otherwise) }\end{array}$ & Increase \\
\hline Hunger score & Hunger score & $\begin{array}{l}\text { (1) Thinking now only about the PAST FOUR } \\
\text { WEEKS, how often did you or any member } \\
\text { of your household go to bed at night hungry } \\
\text { because there was not enough food? (2) Thinking } \\
\text { again about the PAST FOUR WEEKS, how often } \\
\text { did you or any member of your household have } \\
\text { to eat less than normal or eat less expensive food } \\
\text { because of lack of money or harvest from your } \\
\text { land? Scored: } 3 \text {. Often (more than } 10 \text { times); } 2 \text {. } \\
\text { Sometimes (3-10 times); } 1 \text {. Rarely (1-2 times); } \\
0 . \text { Never }\end{array}$ & 2 & $\begin{array}{l}\text { Mean score } \\
\text { (sum of two } \\
\text { items) }\end{array}$ & Reduced \\
\hline Parenting & & & & & \\
\hline
\end{tabular}




\begin{tabular}{|c|c|c|c|c|c|}
\hline Women & Men & How assessed & $\begin{array}{l}\text { Items, } \\
\mathrm{n}\end{array}$ & $\begin{array}{l}\text { Method of } \\
\text { scaling }\end{array}$ & $\begin{array}{l}\text { Hypothesised } \\
\text { direction }\end{array}$ \\
\hline $\begin{array}{l}\text { Endorses statements supporting } \\
\text { physical punishment of children }\end{array}$ & $\begin{array}{l}\text { Endorses statements supporting } \\
\text { physical punishment of children }\end{array}$ & $\begin{array}{l}\text { In your opinion, how important is physical } \\
\text { discipline in raising a well-behaved and moral } \\
\text { child. Would you say } 1 . \text { Very important; } 2 \text {. } \\
\text { Important; } 3 \text {. Somewhat important; } 4 \text {. Not } \\
\text { necessary at all }\end{array}$ & 1 & $\begin{array}{l}\text { Binary (coded } \\
\text { one for } \\
\text { answers of } \\
\text { 'Important' } \\
\text { or 'Very } \\
\text { Important', } 0 \\
\text { otherwise) }\end{array}$ & Reduced \\
\hline $\begin{array}{l}\text { Reports punishing children by } \\
\text { smacking or beating them }\end{array}$ & $\begin{array}{l}\text { Reports punishing children by } \\
\text { smacking or beating them }\end{array}$ & $\begin{array}{l}\text { In the past } 12 \text { months how often do you or } \\
\text { your husband punish children in your home by } \\
\text { smacking or beating them? } 1 \text {. Very Often; } 2 \text {. } \\
\text { Often; } 3 \text {. Sometimes; } 4 \text {. Never }\end{array}$ & 1 & $\begin{array}{l}\text { Binary (coded } \\
0 \text { for 'never' } \\
\text { and one } \\
\text { otherwise) }\end{array}$ & Reduced \\
\hline
\end{tabular}

Health-related outcomes

\begin{tabular}{|c|c|c|c|c|c|}
\hline Self-rated health & Self-rated health & $\begin{array}{l}\text { Overall, would you describe your current health } \\
\text { as: } 1 \text {. Excellent; } 2 \text {. Good; 3. Fair; 4. Poor; } 5 \text {. Very } \\
\text { poor }\end{array}$ & 1 & $\begin{array}{l}\text { Binary (coded } \\
\text { one for 'Good' } \\
\text { or 'Excellent', } \\
0 \text { otherwise) }\end{array}$ & Increase \\
\hline PTSD symptoms* & PTSD symptoms & $\begin{array}{l}\text { Abbreviated PTSD Checklist-Civilian. }{ }^{35} 36 \\
\text { Typical } \\
\text { item, "In the past month, how much have you } \\
\text { been bothered by repeated, disturbing memories, } \\
\text { thoughts, or images of a stressful experience } \\
\text { from the past?" (possible range } 6-30 \text { ) }\end{array}$ & 6 & $\begin{array}{l}\text { Mean score } \\
\text { (Cronbach's } \\
\text { alpha for } \\
\text { scale: } 0.83 \text { for } \\
\text { women, } 0.80 \\
\text { for men) }\end{array}$ & Reduced \\
\hline Problematic alcohol use* & Assessed as secondary outcome & $\begin{array}{l}\text { Alcohol Use Disorder Identification Test- } \\
\text { Consumption (AUDIT-C) }{ }^{4344} \text { Scores of } 0 \text { assigned } \\
\text { to non-drinkers. Assessed for men at all time } \\
\text { points; added for women at midline and endline } \\
\text { only. (possible range } 0-12 \text { ) }\end{array}$ & 3 & $\begin{array}{l}\text { Binary (coded } \\
1 \text { for score of } \\
4 \text { or higher, } \\
0 \text { otherwise } \\
\text { and for non- } \\
\text { drinkers) }\end{array}$ & Reduced \\
\hline
\end{tabular}

*Added after baseline at the request of community partners, who wanted the information for programming purposes. IPV, intimate partner violence; PSTD, post-traumatic stress disorder.

experienced any distress, with services offered either in person, over the phone or via referral at a later time. She also provided regular debriefing sessions for fieldwork staff. All deaths and other serious adverse events discovered to have occurred among study participants during follow-up data collection were investigated for possible relationship to study participation.

\section{Patient and public involvement}

Our community partner organisations, CARE Rwanda, RWAMREC and RWN participated in framing the research questions and planning operational logistics. They were active collaborators on our accompanying qualitative research and process evaluations, including validating the analysis and formulating recommendations. ${ }^{13} 142125-28$ The Indashyikirwa programme and the impact evaluation were overseen by a programme advisory committee chaired by the Rwandan Ministry of Gender and Family Planning (MIGEPROF), with active engagement of civil society representatives. Findings presented here were workshopped in Rwanda with stakeholders from civil society, government, multilateral agencies and research organisations before submission for publication.

\section{RESULTS}

In total, 1660 women ( 828 intervention and 832 control) were successfully enrolled in the impact evaluation at baseline $(98.8 \%$ of the target of 1680). Among men, 1651 participants (821 intervention and 830 control) enrolled (98.3\% of the target of 1680$)$. Recruitment took place during a predefined period from 23 November 2015 to 13 January 2016; intervention participants were recruited before control participants to ensure that baseline data collection could be completed in advance of a target implementation date set by the Rwandan Ministry of Gender and Family Promotion (MIGEPROF) in their role coordinating the programme advisory committee. Figure 2 describes the retention of study participants over time. At 12 months, overall retention of women was $99.0 \%$ with slightly more intervention than control participants interviewed $(99.6 \%$ vs $98.3 \%, \mathrm{p}=0.004)$. At 24 months, $97.4 \%$ of women were retained, again with slightly higher retention in the intervention than control arm $(98.4 \%$ vs $96.4 \%, \mathrm{p}=0.007)$. Among men, overall retention was $96.7 \%$ at 12 months and $93.0 \%$ at 24 months, with no significant difference between study arms. In total, 1647 women and 1622 men contributed data at one or both follow-up time points and were included in our outcome modelling.

Table 2 describes the sociodemographic characteristics of participants at baseline. Among both women and men, participants in the control arm were more likely to report that both spouses belonged to a VSLA. Among women, $35.3 \%$ of intervention versus $47.6 \%$ of control participants reported that both spouses were VSLA members $(p=0.02)$; whereas among men, the difference was $46.7 \%$ intervention versus $57.4 \%$ control $(\mathrm{p}=0.04)$. 


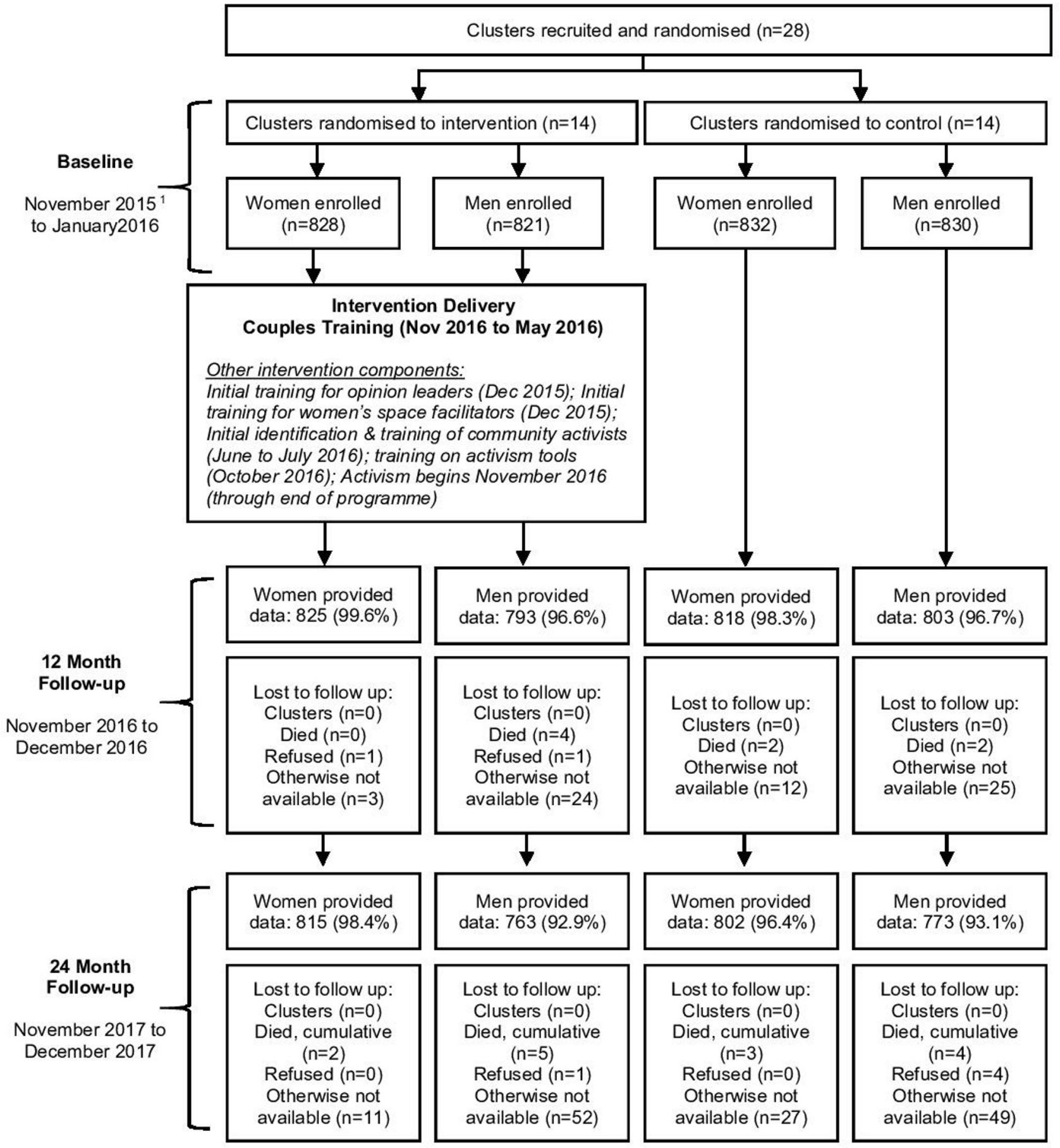

${ }^{1}$ Enrolment of intervention arm was completed within each sector before any intervention activities were undertaken. For the baseline round of data collection only, to meet the need of programmatic timelines, intervention arm data collection was fully completed before control arm data collection was commenced. At both 12 and 24 months, data collection was organised by geography only.

Figure 2 Indashyikirwa couples' cohort CONSORT (Consolidated Standards of Reporting Trials) diagram showing flow of study enrolment and retention over time.

Table 3 describes baseline demographic characteristics associated with loss to follow-up. Among women, those lost to follow-up had lower household assets scores at baseline $(\mathrm{p}=0.004)$ and were more likely to have reported experiences of physical or sexual IPV with a previous partner
(20.9\% vs $12.8 \%, \mathrm{p}=0.05)$. Among men, those lost to follow-up were more likely to have been cohabiting versus legally married at baseline $(p=0.003)$, had lower baseline scores on household assets $(\mathrm{p}=0.02)$ and were more likely to report being beaten often or very often as a child $(\mathrm{p}=0.02)$. 
Table 2 Sociodemographic characteristics at baseline of women and men enrolled in the Indashyikirwa couples' cohort, by study arm

\begin{tabular}{|c|c|c|c|c|c|c|c|c|c|c|}
\hline \multirow[b]{3}{*}{ Variable } & \multicolumn{5}{|l|}{ Women } & \multicolumn{5}{|l|}{ Men } \\
\hline & \multicolumn{2}{|l|}{$\begin{array}{l}\text { Control } \\
(\mathrm{N}=832)\end{array}$} & \multicolumn{2}{|c|}{$\begin{array}{l}\text { Intervention } \\
(\mathrm{N}=\mathbf{8 2 8})\end{array}$} & \multirow[b]{2}{*}{$P$ value } & \multicolumn{2}{|l|}{$\begin{array}{l}\text { Control } \\
(\mathrm{N}=830)\end{array}$} & \multicolumn{2}{|c|}{$\begin{array}{l}\text { Intervention } \\
(\mathrm{N}=\mathbf{8 2 1})\end{array}$} & \multirow[b]{2}{*}{$P$ value } \\
\hline & $\mathrm{N}$ or mean & $\begin{array}{l}\% \text { or } \\
\text { (SE) }\end{array}$ & $\begin{array}{l}\mathrm{N} \text { or } \\
\text { mean }\end{array}$ & $\%$ or (SE) & & $\mathrm{N}$ or mean & $\%$ or (SE) & $\begin{array}{l}\mathrm{N} \text { or } \\
\text { mean }\end{array}$ & $\%$ or (SE) & \\
\hline \multicolumn{11}{|l|}{ Age of respondents } \\
\hline Mean age & 32.5 & $(0.29)$ & 31.9 & $(0.30)$ & 0.32 & 35.4 & $(0.29)$ & 35.7 & $(0.38)$ & 0.55 \\
\hline$\leq 25$ years & 142 & $17.1 \%$ & 123 & $14.9 \%$ & 0.57 & 68 & $8.2 \%$ & 55 & $6.70 \%$ & 0.64 \\
\hline $26-35$ years & 424 & $51.0 \%$ & 428 & $51.7 \%$ & & 379 & $45.7 \%$ & 381 & $46.4 \%$ & \\
\hline$>35$ years & 266 & $32.0 \%$ & 277 & $33.5 \%$ & & 383 & $46.1 \%$ & 385 & $46.9 \%$ & \\
\hline \multicolumn{11}{|l|}{ Education } \\
\hline No school & 151 & $18.4 \%$ & 137 & $16.8 \%$ & 0.67 & 121 & $14.8 \%$ & 144 & $17.7 \%$ & 0.41 \\
\hline Primary (complete) & 548 & $66.8 \%$ & 567 & $69.7 \%$ & & 552 & $67.3 \%$ & 536 & $65.9 \%$ & \\
\hline Secondary (complete) & 95 & $11.6 \%$ & 81 & $10.0 \%$ & & 95 & $11.6 \%$ & 83 & $10.2 \%$ & \\
\hline Other schooling & 26 & $3.2 \%$ & 29 & $3.6 \%$ & & 52 & $6.3 \%$ & 50 & $6.2 \%$ & \\
\hline \multicolumn{11}{|l|}{ Relationship status } \\
\hline Married & 523 & $62.9 \%$ & 573 & $69.2 \%$ & 0.15 & 530 & $63.9 \%$ & 565 & $68.8 \%$ & 0.29 \\
\hline Living as if married & 309 & $37.1 \%$ & 255 & $30.8 \%$ & & 300 & $36.1 \%$ & 256 & $31.2 \%$ & \\
\hline \multicolumn{11}{|l|}{ VSLA membership } \\
\hline Wife & 302 & $36.3 \%$ & 409 & $49.4 \%$ & 0.02 & 198 & $23.9 \%$ & 288 & $35.1 \%$ & 0.04 \\
\hline Husband & 134 & $16.1 \%$ & 127 & $15.3 \%$ & & 155 & $18.7 \%$ & 150 & $18.3 \%$ & \\
\hline Both & 396 & $47.6 \%$ & 292 & $35.3 \%$ & & 477 & $57.5 \%$ & 383 & $46.7 \%$ & \\
\hline \multicolumn{11}{|l|}{ Household assets } \\
\hline Bicycle & 269 & $32.7 \%$ & 273 & $33.3 \%$ & 0.93 & 270 & $32.5 \%$ & 273 & $33.3 \%$ & 0.92 \\
\hline Cell phone & 657 & $79.7 \%$ & 668 & $81.5 \%$ & 0.57 & 662 & $79.8 \%$ & 668 & $81.5 \%$ & 0.58 \\
\hline Radio & 541 & $65.7 \%$ & 535 & $65.2 \%$ & 0.92 & 545 & $65.7 \%$ & 535 & $65.2 \%$ & 0.91 \\
\hline Electricity & 151 & $18.3 \%$ & 180 & $22.0 \%$ & 0.49 & 153 & $18.4 \%$ & 180 & $22.0 \%$ & 0.50 \\
\hline HH has livestock & 486 & $58.4 \%$ & 477 & $57.6 \%$ & 0.84 & 484 & $58.5 \%$ & 487 & $59.5 \%$ & 0.79 \\
\hline $\mathrm{HH}$ owns land & 534 & $64.2 \%$ & 521 & $62.9 \%$ & 0.75 & 559 & $67.4 \%$ & 560 & $68.2 \%$ & 0.84 \\
\hline HH owns home & 713 & $85.7 \%$ & 721 & $87.1 \%$ & 0.44 & 737 & $88.9 \%$ & 735 & $89.6 \%$ & 0.65 \\
\hline $\begin{array}{l}\text { Weighted assets score* } \\
\text { (range } 0-15.2 \text { ) }\end{array}$ & 6.90 & $(.31)$ & 7.09 & (.29) & 0.65 & 6.88 & $(0.32)$ & 7.12 & $(0.30)$ & 0.58 \\
\hline \multicolumn{11}{|l|}{ Who earns more } \\
\hline Husband more & 377 & $45.4 \%$ & 363 & $43.8 \%$ & 0.58 & 232 & $28.0 \%$ & 205 & $25.0 \%$ & 0.66 \\
\hline About the same & 57 & $6.9 \%$ & 71 & $8.6 \%$ & & 70 & $8.4 \%$ & 63 & $7.7 \%$ & \\
\hline Wife more & 71 & $8.5 \%$ & 81 & $9.8 \%$ & & 69 & $8.3 \%$ & 77 & $9.4 \%$ & \\
\hline Do all work together & 326 & $39.2 \%$ & 313 & $37.8 \%$ & & 458 & $55.3 \%$ & 475 & $57.9 \%$ & \\
\hline \multicolumn{11}{|l|}{ Previous experience of violence } \\
\hline $\begin{array}{l}\text { Experienced physical or } \\
\text { sexual IPV with a past } \\
\text { partner (prior to current } \\
\text { relationship) }\end{array}$ & 97 & $11.7 \%$ & 118 & $14.4 \%$ & 0.21 & 91 & $11.0 \%$ & 113 & $13.8 \%$ & 0.17 \\
\hline Any prior sexual violence $\dagger$ & 404 & $48.8 \%$ & 406 & $49.1 \%$ & 0.94 & $\begin{array}{l}\text { Not } \\
\text { assessed }\end{array}$ & & & & \\
\hline $\begin{array}{l}\text { Witnessed mother being } \\
\text { beaten }\end{array}$ & $\begin{array}{l}\text { Not } \\
\text { assessed }\end{array}$ & & & & & 356 & $42.9 \%$ & 365 & $44.6 \%$ & 0.61 \\
\hline $\begin{array}{l}\text { Beaten often or very often } \\
\text { as a child }\end{array}$ & $\begin{array}{l}\text { Not } \\
\text { assessed }\end{array}$ & & & & & 236 & $28.4 \%$ & 230 & $28.1 \%$ & 0.90 \\
\hline
\end{tabular}

*Weighted asset score constructed by weighting each listed asset with its inverse frequency among participants and then summing weights for assets owned (ie, something owned by $50 \%$ of participants was weighted at 2.0 and something owned by $25 \%$ of participants weighted at 4.0 ; these weights were then summed for each asset owned).

†Defined as forced first sex, forced sex by a non-partner at any age, unwanted sexual touching at age $<15$.

$\mathrm{HH}$, household; IPV, intimate partner violence; VLSA, village savings and loan association. 
Table 3 Sociodemographic characteristics at baseline of women and men enrolled in the Indashyikirwa couples' cohort comparing those retained to those lost to follow-up

\begin{tabular}{|c|c|c|c|c|c|c|c|c|c|c|}
\hline \multirow[b]{3}{*}{ Variable } & \multicolumn{5}{|c|}{ Women } & \multicolumn{5}{|l|}{ Men } \\
\hline & \multicolumn{2}{|c|}{$\begin{array}{l}\text { Retained } \\
(\mathrm{N}=1617)\end{array}$} & \multicolumn{2}{|l|}{$\begin{array}{l}\text { Lost } \\
(\mathrm{N}=43)\end{array}$} & \multirow[b]{2}{*}{$P$ value } & \multicolumn{2}{|l|}{$\begin{array}{l}\text { Retained } \\
(\mathrm{N}=1536)\end{array}$} & \multicolumn{2}{|c|}{$\begin{array}{l}\text { Lost } \\
(\mathrm{N}=115)\end{array}$} & \multirow[b]{2}{*}{$P$ value } \\
\hline & $\begin{array}{l}\mathrm{N} \text { or } \\
\text { mean }\end{array}$ & $\%$ or (SE) & $\begin{array}{l}\mathrm{N} \text { or } \\
\text { mean }\end{array}$ & $\%$ or (SE) & & $\mathrm{N}$ or mean & $\%$ or (SE) & $\begin{array}{l}\mathrm{N} \text { or } \\
\text { mean }\end{array}$ & $\%$ or (SE) & \\
\hline \multicolumn{11}{|l|}{ Age of respondents } \\
\hline Mean age & 32.7 & $(0.22)$ & 31.6 & $(0.80)$ & 0.18 & 35.6 & $(0.23)$ & 35.0 & $(0.88)$ & 0.51 \\
\hline$\leq 25$ years & 256 & $15.8 \%$ & 9 & $20.9 \%$ & 0.63 & 112 & $7.3 \%$ & 11 & $9.6 \%$ & 0.59 \\
\hline $26-35$ years & 831 & $51.4 \%$ & 21 & $48.8 \%$ & & 705 & $45.9 \%$ & 55 & $47.8 \%$ & \\
\hline$>35$ years & 530 & $32.8 \%$ & 13 & $30.2 \%$ & & 719 & $46.8 \%$ & 49 & $42.6 \%$ & \\
\hline \multicolumn{11}{|l|}{ Education } \\
\hline No school & 281 & $17.6 \%$ & 7 & $17.1 \%$ & 0.36 & 239 & $15.7 \%$ & 26 & $23.0 \%$ & 0.08 \\
\hline Primary (complete) & 1090 & $68.4 \%$ & 25 & $61.0 \%$ & & 1019 & $67.0 \%$ & 69 & $61.1 \%$ & \\
\hline Secondary (complete) & 168 & $10.6 \%$ & 8 & $19.5 \%$ & & 170 & $11.2 \%$ & 8 & $7.1 \%$ & \\
\hline Other schooling & 54 & $3.4 \%$ & $\ddagger$ & $2.4 \%$ & & 92 & $6.1 \%$ & 10 & $8.9 \%$ & \\
\hline \multicolumn{11}{|l|}{ Relationship status } \\
\hline Married & 1072 & $66.3 \%$ & 24 & $55.8 \%$ & 0.17 & 1030 & $67.1 \%$ & 65 & $56.5 \%$ & 0.003 \\
\hline Living as if married & 545 & $33.7 \%$ & 19 & $44.2 \%$ & & 506 & $32.9 \%$ & 50 & $43.5 \%$ & \\
\hline \multicolumn{11}{|l|}{ VSLA membership } \\
\hline Wife & 692 & $42.8 \%$ & 19 & $44.2 \%$ & 0.82 & 445 & $29.0 \%$ & 41 & $35.7 \%$ & 0.32 \\
\hline Husband & 253 & $15.7 \%$ & 8 & $18.6 \%$ & & 288 & $18.8 \%$ & 17 & $14.8 \%$ & \\
\hline Both & 672 & $41.6 \%$ & 16 & $37.2 \%$ & & 803 & $52.3 \%$ & 57 & $49.6 \%$ & \\
\hline \multicolumn{11}{|l|}{ Household assets } \\
\hline Bicycle & 532 & $33.2 \%$ & 10 & $23.8 \%$ & 0.17 & 511 & $33.3 \%$ & 32 & $27.8 \%$ & 0.28 \\
\hline Cell phone & 1296 & $80.9 \%$ & 29 & $69.1 \%$ & 0.03 & 1248 & $81.3 \%$ & 82 & $71.3 \%$ & 0.02 \\
\hline Radio & 1054 & $65.8 \%$ & 22 & $52.4 \%$ & 0.10 & 1017 & $66.3 \%$ & 63 & $54.8 \%$ & 0.04 \\
\hline Electricity & 324 & $20.2 \%$ & 7 & $16.7 \%$ & 0.54 & 314 & $20.5 \%$ & 19 & $16.5 \%$ & 0.32 \\
\hline $\mathrm{HH}$ has livestock & 946 & $58.5 \%$ & 17 & $39.5 \%$ & 0.03 & 913 & $59.6 \%$ & 58 & $50.9 \%$ & 0.06 \\
\hline HH owns land & 1038 & $64.2 \%$ & 17 & $39.5 \%$ & $<0.001$ & 1054 & $68.6 \%$ & 65 & $56.5 \%$ & 0.01 \\
\hline HH owns home & 1406 & $87.0 \%$ & 28 & $65.1 \%$ & $<0.001$ & 1375 & $89.6 \%$ & 97 & $84.4 \%$ & 0.04 \\
\hline $\begin{array}{l}\text { Weighted assets score* } \\
\text { (range } 0-15.2 \text { ) }\end{array}$ & 7.0 & $(0.19)$ & 5.2 & $(0.65)$ & 0.004 & 7.1 & $(0.18)$ & 6.06 & $(0.48)$ & 0.02 \\
\hline \multicolumn{11}{|l|}{ Who earns more } \\
\hline Husband more & 721 & $44.6 \%$ & 19 & $44.2 \%$ & 0.91 & 400 & $26.1 \%$ & 37 & $32.2 \%$ & 0.46 \\
\hline About the same & 125 & $7.7 \%$ & 3 & $7.0 \%$ & & 123 & $8.0 \%$ & 10 & $8.7 \%$ & \\
\hline Wife more & 147 & $9.1 \%$ & 5 & $11.6 \%$ & & 136 & $8.9 \%$ & 10 & $8.7 \%$ & \\
\hline Do all work together & 623 & $38.6 \%$ & 16 & $37.2 \%$ & & 875 & $57.0 \%$ & 58 & $50.4 \%$ & \\
\hline \multicolumn{11}{|l|}{ Previous experience of violence } \\
\hline $\begin{array}{l}\text { Experienced physical or } \\
\text { sexual IPV with a past } \\
\text { partner (prior to current } \\
\text { relationship) }\end{array}$ & 206 & $12.8 \%$ & 9 & $20.9 \%$ & 0.05 & 191 & $12.5 \%$ & 13 & $11.3 \%$ & 0.70 \\
\hline Any prior sexual violence $\dagger$ & 784 & $48.6 \%$ & 26 & $60.5 \%$ & 0.08 & $\begin{array}{l}\text { Not } \\
\text { assessed }\end{array}$ & & & & \\
\hline $\begin{array}{l}\text { Witnessed mother being } \\
\text { beaten }\end{array}$ & & & & & & 673 & $43.9 \%$ & 48 & $42.1 \%$ & 0.71 \\
\hline $\begin{array}{l}\text { Beaten often or very often as } \\
\text { a child }\end{array}$ & & & & & & 425 & $27.7 \%$ & 41 & $35.7 \%$ & 0.02 \\
\hline
\end{tabular}

*Weighted asset score constructed by weighting each listed asset with its inverse frequency among participants and then summing weights for assets owned (ie, something owned by $50 \%$ of participants was weighted at 2.0 and something owned by $25 \%$ of participants weighted at 4.0 ; these weights were then summed for each asset owned).

†Defined as forced first sex, forced sex by a non-partner at any age, unwanted sexual touching at age $<15$.

$\neq$ Cell size too small to report

$\mathrm{HH}$, household; IPV, intimate partner violence; VSLA, village savings and loan association. 


\section{Primary outcome}

The results of all outcome models for women are given in table 4 and for men in table 5 . Women who participated in the couples' curriculum, compared with women in the control, reported a significant reduction in experience of physical and/or sexual IPV at both the interim 12-month point and the final 24-month time point $(\mathrm{aRR}=0.44 ; 95 \%$ CI 0.34 to 0.59$)$. Men who participated in the couples' curriculum also reported a significant reduction in perpetration of physical and/or sexual IPV compared with men in the control, again at both the interim assessment and with a significant intervention effect sustained at 24 months $(\mathrm{aRR}=0.54 ; 95 \%$ CI 0.38 to 0.75$)$.

\section{Secondary outcomes}

\section{Secondary outcomes: IPV-related}

Among the women in the couples' cohort who reported no experience of IPV in the 12 months prior to the intervention, there was a significant reduction in IPV in the intervention versus control group at the 12-month midpoint, but this was non-significant by 24 months $(\mathrm{aRR}=0.74 ; 95 \%$ CI 0.46 to 1.17$)$. Among the women who did report experience of IPV at baseline, there was a significant reduction in intervention vs control at both the 12-month midpoint and the final 24-month assessment $(\mathrm{aRR}=0.35 ; 95 \%$ CI 0.20 to 0.61$)$. Among the men in the couples' cohort who reported no perpetration of IPV in the 12 months prior to the intervention, there was a marginally significant reduction in IPV in the intervention vs control group at the 12-month midpoint, but this was non-significant by 24 months. Among men who did report perpetration of IPV at baseline, there was a significant reduction in the intervention versus control group at both the 12-month midpoint and the final 24-month assessment $(\mathrm{aRR}=0.35 ; 95 \%$ CI 0.17 to 0.72$)$.

Female intervention participants compared with control group participants reported less experience of any physical IPV, any forced or coerced sex (sexual IPV), and any economic abuse at both the 12-month interim assessment and the final 24-month timepoint; experience of emotional aggression was significantly reduced at the 24-month endpoint only. Among male participants, there was a significant reduction in perpetration of physical IPV at the 12-month interim measure that was nonsignificant by the 24-month final assessment. In contrast, there was a significant impact on the perpetration of forced or coerced sex (sexual IPV) that was sustained at the 24-month final assessment. There was no difference between the intervention and control groups on men's self-reported perpetration of economic abuse.

Among women who reported children under 18 residing in the household and had experienced physical or sexual IPV in the past 12 months, there were significant reductions in reports of children witnessing the mother being beaten that were significant at both the 12-month interim measures and the final 24-month assessment. There was no significant difference between the intervention and control arms on the rate of help seeking among women who had experienced any physical or sexual IPV in the past 12 months.

Secondary outcomes: relationship quality

Both women and men in the intervention arm compared with the control arm reported statistically significant improvements in measures of relationship quality, with decreased scores for the level of conflict in the relationship, and increased scores on effective conflict management strategies, with improvements at both 12 and 24 months. Female intervention participants were also more likely to report the maximum possible score on measures of couple communication and trust at both the interim 12-month and the final 24-month assessments. Among men, the intervention versus control participants showed significant improvements in couple communication at both time points, but no significant difference in perception of trust at either time point.

\section{Secondary outcomes: beliefs and community engagement}

Female and male intervention participants versus control group participants both reported significant reductions in the number of reasons endorsed to justify wife beating at both time points. Female intervention participants also reported significantly increased scores on self-efficacy for community engagement at both time points (not assessed for men). Men reported an increase in giving advice to neighbours about relationships at both 12 and 24 months, but only reported increased confidence for doing so at 24 months. Both female and male intervention participants reported increases in actions to prevent IPV at both time points. Among men, those who selfreported participation in the activist training were more likely to report this at 24 months than those reported participating in the couple's training only, but this difference was non-significant for women.

\section{Exploratory outcomes}

\section{Exploratory outcomes: household economic status}

Male and female intervention participants both reported increased cash income and household food security, the latter accompanied by overall reductions in household scores for hunger. Both reported a slight increase in payment of any household debt in the last month at the interim 12-month assessment, but there was no difference at 24 months.

\section{Exploratory outcomes: parenting}

Both women and men in the intervention arm reported significantly less endorsement of physical discipline in raising children and significantly reduced frequency of smacking or beating children in the home as compared with the control arm. These benefits were present at both the 12-month interim assessment and the final 24-month assessment.

\section{Exploratory outcomes: health related}

Both women and men in the intervention arm versus control were more likely to report 'good' or 'excellent' 


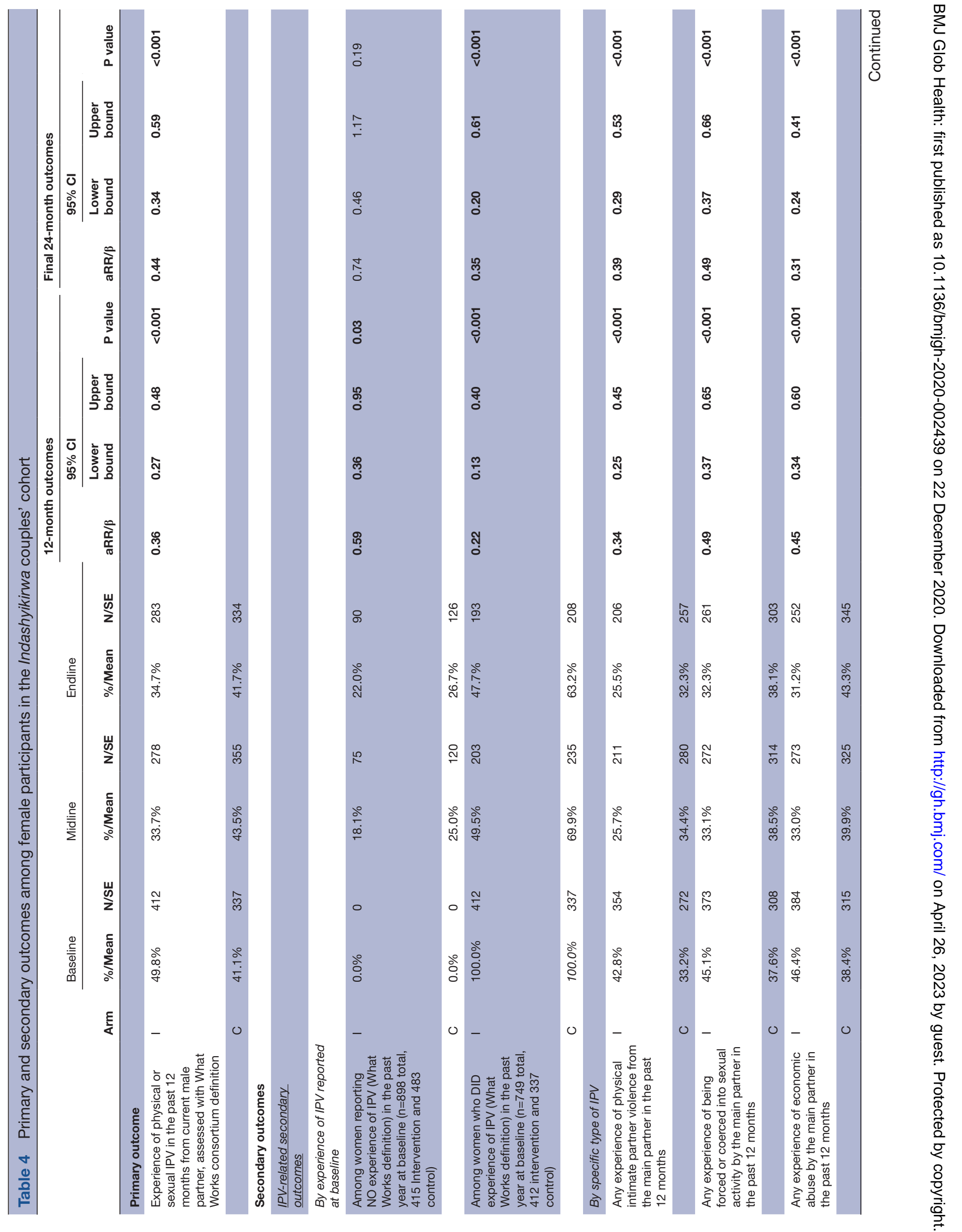




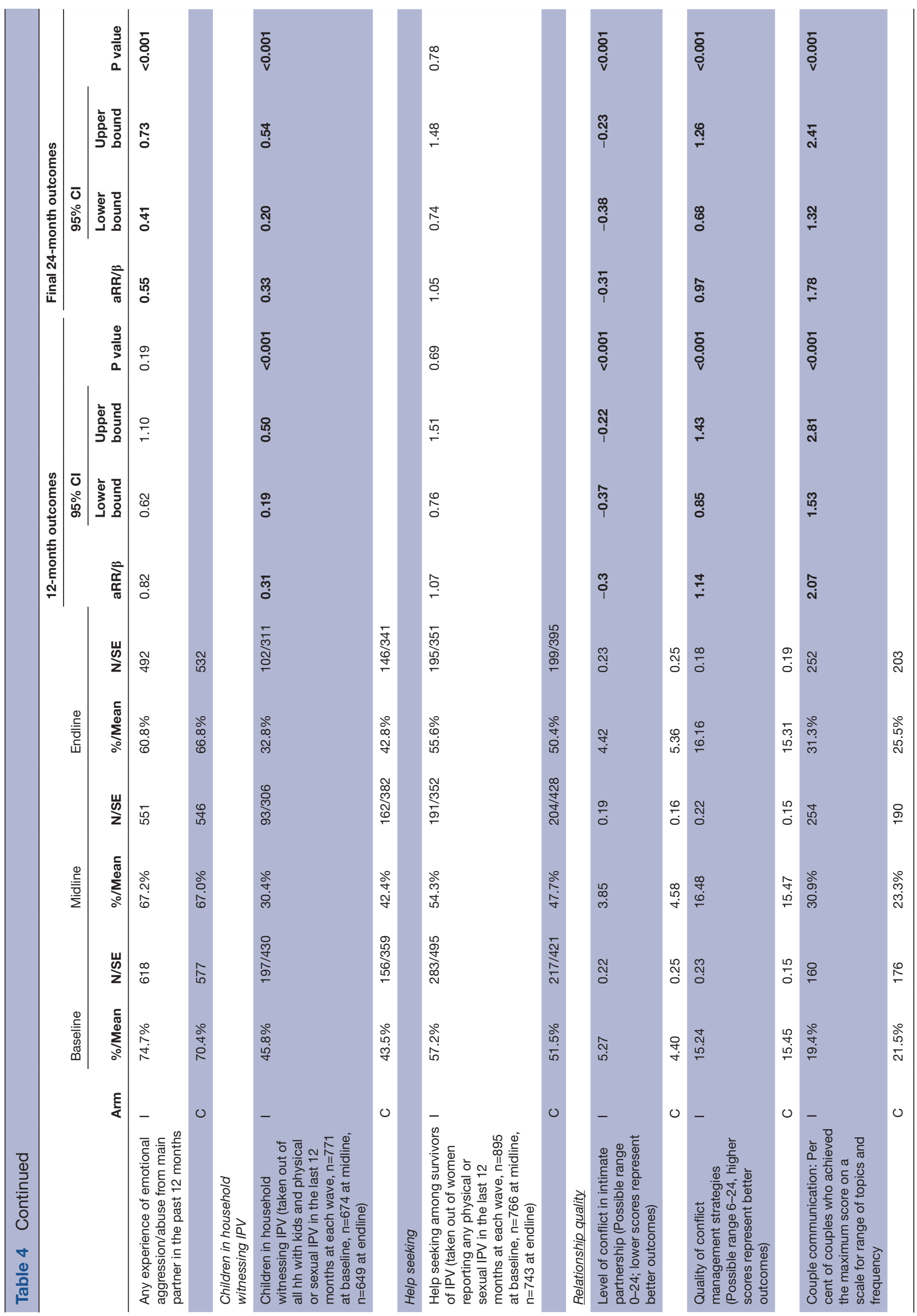

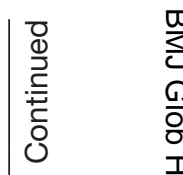




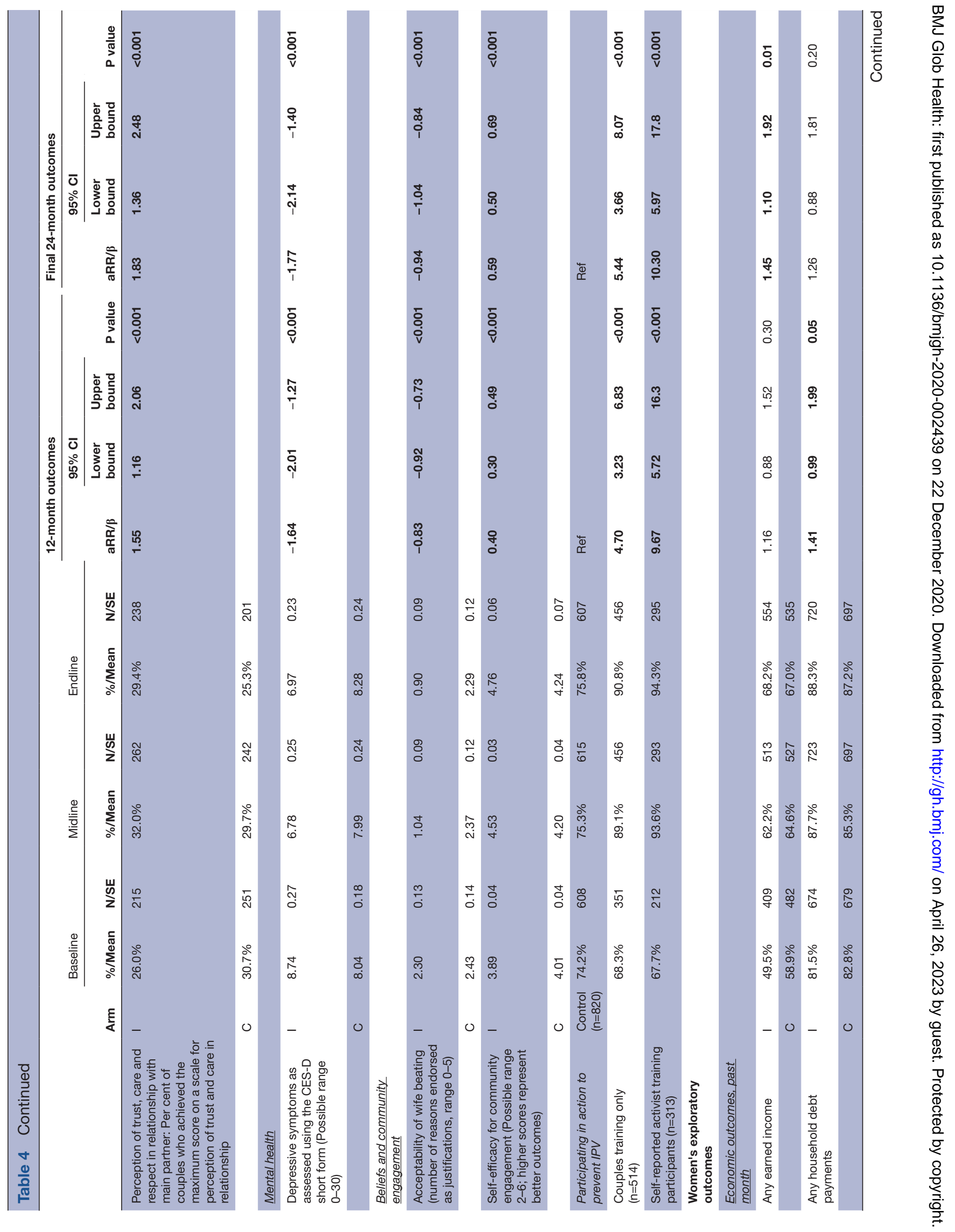




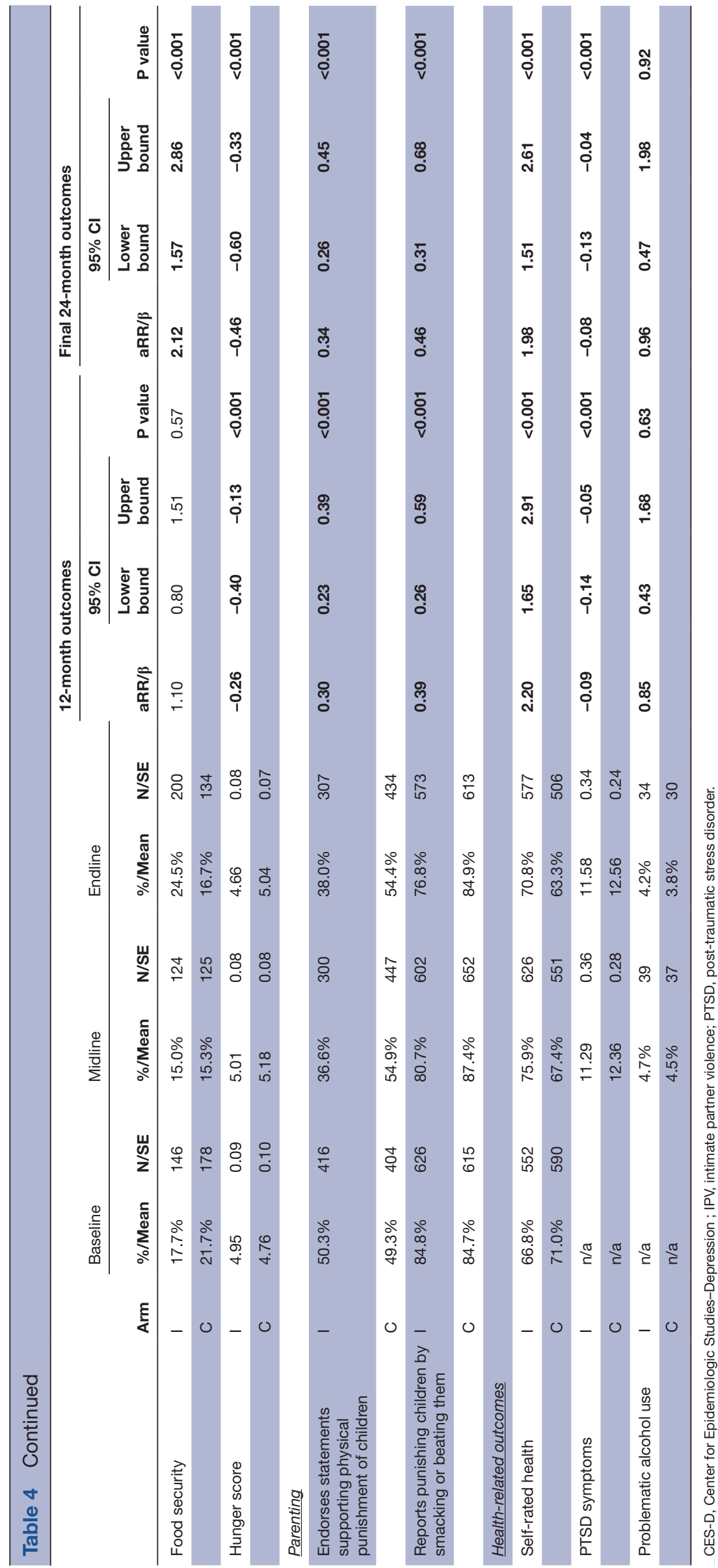

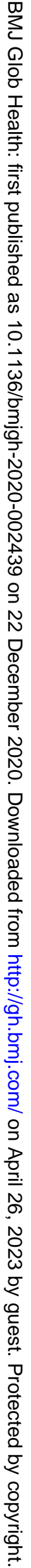




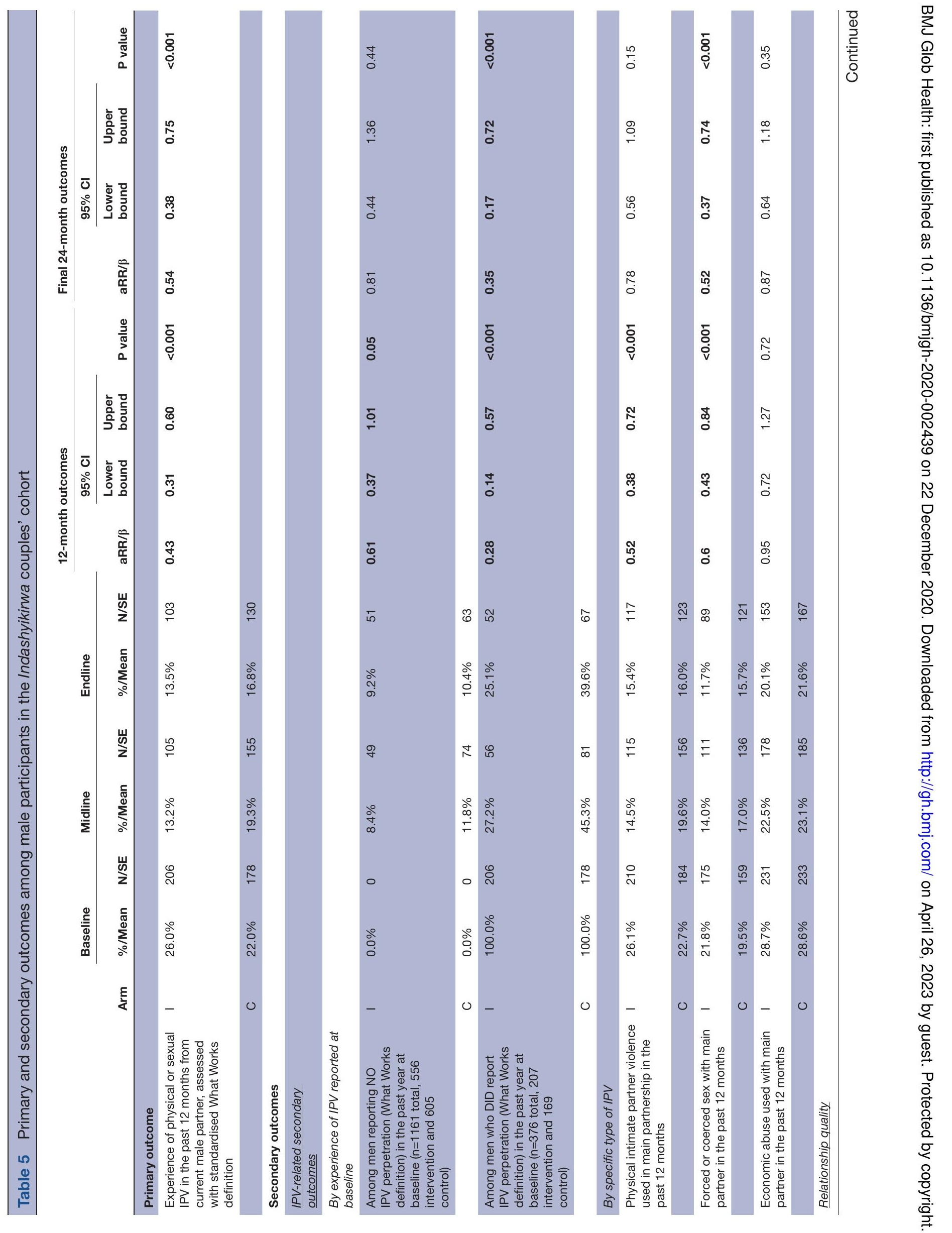




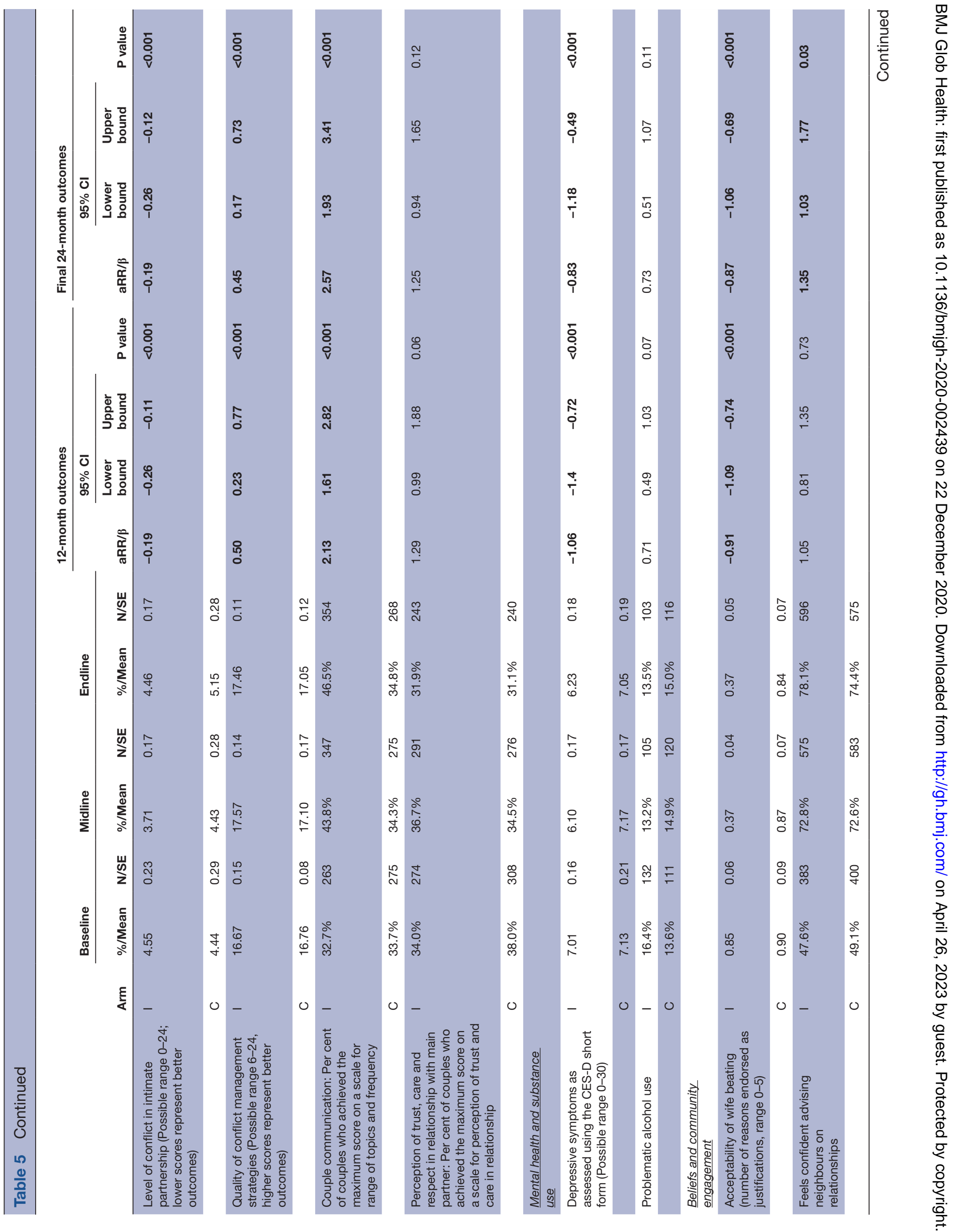




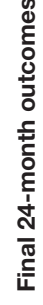

$\frac{0}{\frac{2}{5}}$

$\bar{c}$
$\dot{0}$
$\dot{0}$
$\dot{v}$

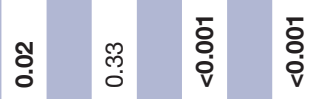

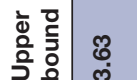

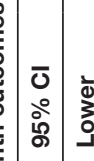

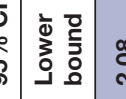

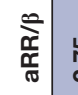

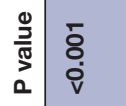

高

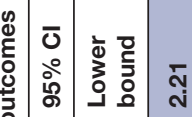

吾

章

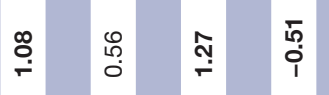

竞

ᄒᄒ

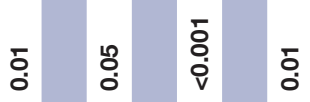

হ⿺辶一兀

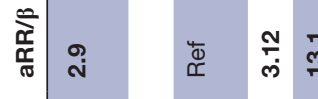

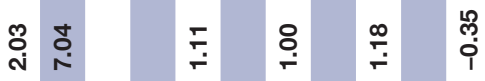

ํㅏㄴ

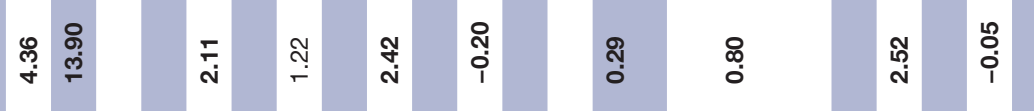

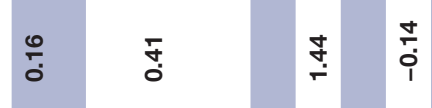

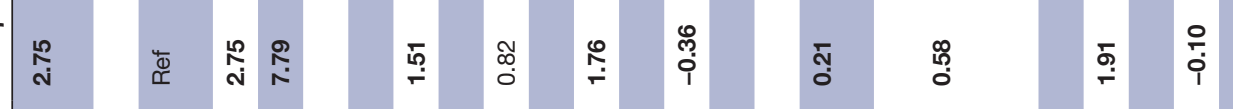

$\begin{array}{ll}\bar{\delta} & \bar{o} \\ \dot{i} & \dot{i}\end{array}$

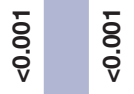

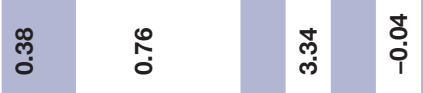

হ̦

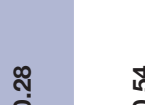

유

峞

হ

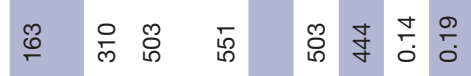

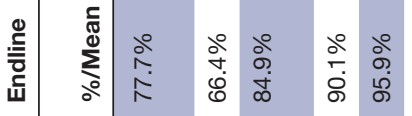

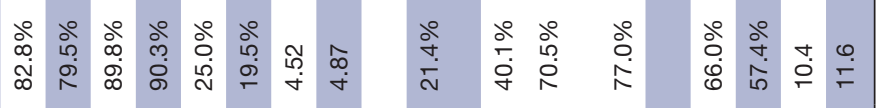

崫

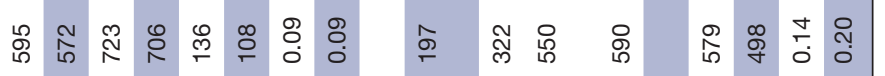

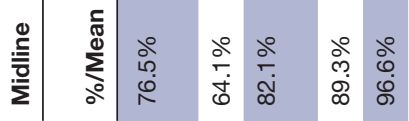

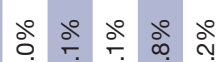

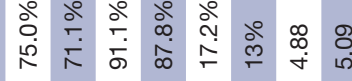

$\infty$
$\infty$
$\stackrel{\infty}{\sim}$

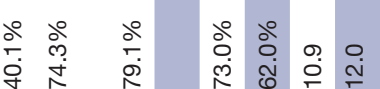

崩

:

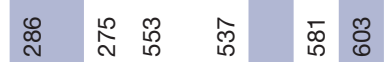

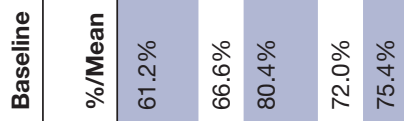

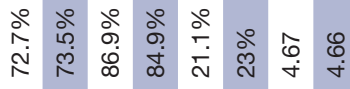

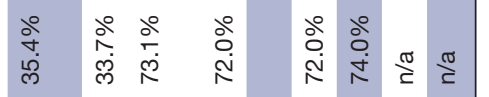

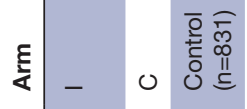

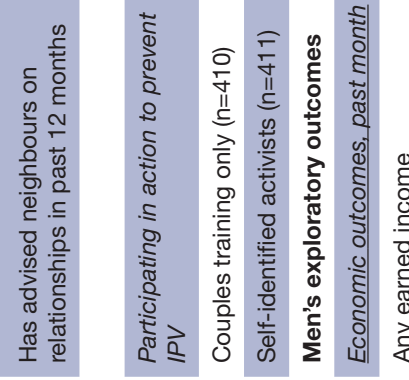

$-0-0-0-0$

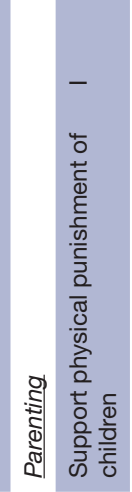

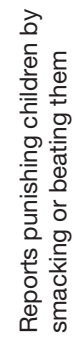

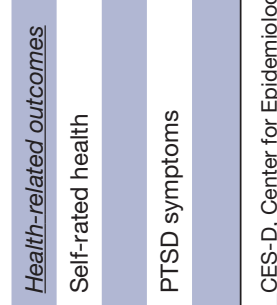

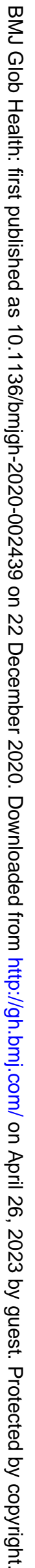


health at both 12-month and 24-month assessments. While PTSD symptoms were not initially assessed, they were added as an exploratory outcome from midline at the request of the programme partners. Both men and women in the intervention versus control groups reported significantly fewer PTSD symptoms at both the 12-month and 24-month time points.

Female intervention participants compared with control group participants reported significantly lower scores on the CES-D 10 short form measuring depressive symptoms with improvements at both interim and final assessments. Male intervention versus control participants also showed significant reductions in CES-D 10 short scores at both time points. There was no significant change in the level of problematic alcohol use (AUDIT-C score $>=4$ ) reported by male participants, although there was a non-significant reduction.

\section{Harms}

A total of 14 deaths occurred ( 5 women and 9 men), with no differences by study arm. One participant was transported for medical attention after a fall at a data collection site that was precipitated by an illness. This accident and all deaths were investigated, reported to ethics committees and found to be unrelated to trial participation. The number of participants referred to the study counsellor was consistently low, with many requesting counselling for events unrelated to study participation. Participants referred were $1.6 \%$ of women at baseline, $1.2 \%$ of women at midline and $0.5 \%$ of women at endline with no significant different between study arms; $<0.2 \%$ of men at all timepoints.

\section{DISCUSSION}

This impact evaluation found substantial and statistically significant overall reductions in the experience of physical and/or sexual IPV at 24 months of follow-up among both women $(\mathrm{aRR}=0.45 ; 95 \%$ CI 0.34 to 0.60$)$ and men $(\mathrm{aRR}=0.53 ; 95 \%$ CI 0.38 to 0.75$)$ who participated in the Indashyikirwa couple's curriculum, which represents a substantial achievement in the prevention of IPV. Detailed results for female participants show statistically significant reductions in both physical IPV and sexual IPV, while for men, significant reductions in reported perpetration were achieved only for sexual IPV at 24 months. Similarly, women participating in the couple's curriculum reported significantly lower risk of experiencing economic abuse not paralleled by men's reports. The discordance between findings among male and female participants in a couple's evaluation is not uncommon, ${ }^{29}{ }^{30}$ and likely reflects some combination of normal differences in perception of events between partners in a relationship and greater willingness to report IPV by women. Data from our qualitative research with couples support this interpretation, where women were also more likely to report experiencing sexual IPV than men were to report perpetrating it, especially at baseline. ${ }^{28}$ However, by the endline interviews, men and women had much more concordant responses around IPV, with a particular increase in the concordance of sexual IPV. This was linked to similar processes of change in response to Indashyikirwa, including greater awareness of various types and consequences of IPV. ${ }^{28}$ It is notable that, per the secondary analysis, the intervention appears to have been more effective at reducing recurrence of IPV among couples who reported IPV in the year prior to baseline than it was at preventing a first occurrence of IPV, although this may have been an issue of statistical power as there is a clear trend towards benefit for both groups.

The findings regarding overall reductions in IPV are bolstered by the findings from both men and women regarding overall improvements in relationship quality. These include decreased relationship conflict, improved conflict management and increased communication among couples attending the curriculum sessions. Female participants also reported increased perception of trust, care and respect with their partners; that this was not mirrored for men likely reflects the higher baseline scores on the measure among them. The qualitative research helps unpack reasons for these improvements, including couples spending greater and more quality time together through co-completing the curriculum, the relationship skills building sessions and use of takehome exercises; the four types of power framework, and the positive, inspiring approach of the curriculum to build healthier, more equitable relationships. ${ }^{25}$ This is important given the consideration of relationship quality as a main pathway for healthy behaviours within couples, ${ }^{31}$ and the evidence that lower quality relationships can be more prone to violence. ${ }^{32} 33$

Women and men who participated in the couple's curriculum also decreased their endorsement of various justifications for wife beating. Women showed increased self-efficacy to engage with community processes; men showed increased confidence and engagement in advising their neighbours on their relationships, and both reported increased participation in actions to prevent IPV. The latter outcome was especially high among those who self-reported engaging as activists after the completion of the couples training. According to the qualitative data, the majority of intervention couples expressed commitment and confidence to prevent and respond to IPV in their communities, and a desire to share their benefits and learnings from the curriculum..$^{25}$ Indeed, far more couples than allowed for in the budget expressed strong interest in serving as Indashyikirwa community activists, and a large number of individuals spontaneously engaged in activist and other outreach activities either on their own or through supporting spouses who had undertaken the formal activist training; these activities were encouraged through the programme. ${ }^{21}$

An important exploratory outcome of the couples' curriculum was the benefits accrued to children in the intervention households. In addition to the overall 
reduction in IPV taking place between parents, mothers who did experience physical and/or sexual IPV reported significant reductions in abuse being witnessed by children. In addition, both women and men decreased their endorsement of corporal punishment of children and reported reduced frequency of smacking or beating children in the household. This is important not only for the well-being of children but also for long-term future prevention of IPV. It is well known that witnessing abuse of a mother and experiencing harsh physical punishments in childhood are strong risk factors for both experience (among women) and perpetration (among men) of IPV later in life. ${ }^{4}$ The qualitative data affirm that negative implications of IPV for children were identified through the couples' curriculum and provided a powerful platform to promote the value of non-violence within families. ${ }^{25} 34$

Other important benefits of couple's participation in Indashyikirwa included improvements in both mental and physical health. Both men and women reported reductions in depressive symptoms on the CES-D 10 scale and improvements in self-rated health. While these results should be interpreted with caution given that both measures are indicative rather than diagnostic, they are highly plausible correlates of the reported improvements in the quality of intimate partnerships and reductions in violence. An additional exploratory finding is the lower scores on the Abbreviated PTSD Checklist-Civilian ${ }^{35}{ }^{36}$ in the intervention versus control couples at both midline and endline. This finding must be interpreted with extreme caution as we did not assess this construct at baseline, but taken together with other findings, it affirms the likely benefit of the couples' curriculum for participants' health. To the extent that the Indashyikirwa couples' curriculum leads to improved health, it is possible that additional benefits in terms of increased productivity and decreased healthcare expenditures could ensue.

A final very important benefit of participating in Indashyikirwa versus the standard VSLA alone was the improvements shown in household well-being in the form of increased income and reduced hunger-also measured as an increase in households considered food secure. There are two possible explanations for this finding, both of which may be simultaneously true. First, the couple's curriculum included explicit content on the value of women's economic empowerment and strategies for shared decision-making around finances. According to the qualitative data, reflecting on the benefits of shared economic decision-making was a powerful alternative to the hegemonic social norm of men holding the primary economic decision-making power. ${ }^{26}$ It is quite plausible that improving couples' ability to function as cooperative economic partners could have improved the overall economic standing of Indashyikirwa households. In addition, participants in the couple's curriculum were paid a stipend of RWF 2000 per person (approximately US\$2) per session which for many households was a large jump in monthly income; we note that only about half of women and three-quarters of men reported any earned income in the past month at baseline. According to the qualitative data, many couples made household investments using this stipend, including purchasing bicycles, livestock and roofing, and emphasised that these improvements were possible through the combined impact of the stipend and the more equitable financial planning and decision-making skills they learnt through the curriculum. ${ }^{37}$ Future efforts to scale up, adapt or implement Indashyikirwa should attempt to tease out the impact of the curriculum on economic development versus the impact of any participation stipends, which may well have functioned here as conditional cash transfers.

\section{Strengths and limitations}

As with all projects, this impact evaluation has a number of limitations and a number of strengths. First, all measures rely on self-reports, making them subject to under-reporting and disclosure bias. Although repeat interviews over time are one way to improve disclosure of IPV, no method completely solves the problem of under-reporting. ${ }^{38}$ There may be social desirability bias around participants wanting to report favourably on an intervention they clearly valued or emphasise what they learnt. We attempted to mitigate this possibility by using anonymous reporting through ACASI data collection, which most participants seemed to find highly acceptable. There is a wealth of evidence that suggests that ACASI encourages more truthful and forthcoming reporting compared with face-to-face interviews or self-administered methods for stigmatised topics, ${ }^{39} 40$ although exceptions have been documented. ${ }^{41}$ Analysis of disclosure of key variables found no difference in prevalence of IPV whether participants completed the interviews via ACASI or face to face, so at minimum we are confident that ACASI did not decrease reporting. We also attempted to mitigate social desirability effects by using field researchers who were external to the programme and emphasising the confidentiality of all answers. Couples who volunteer, especially for programmes requiring long-term commitments, may be more likely than others to benefit and see improvements in their relationships. ${ }^{12} 25$ We were unable to blind participants to the study assignment at the enrolment phase, so this may have resulted in some differential recruitment between arms. While the intervention and control participants were demographically similar at baseline, the two study arms asked participants to volunteer for different tasks (participating in a 22 session curriculum versus research interviews only) which could have prompted different willingness to enrol; control participants were more likely to report that both members of the couple belonged to a VSLA, suggesting that there may have been some systematic difference in who came forward to participate. There was some minor differential loss to follow-up among the couple's cohort participants who were vulnerable 
economically and/or who had experienced violence previously; however, this would tend to bias our findings towards the null hypothesis. Moreover, our excellent cohort retention served to mitigate any significant impact of differential loss to follow-up on the findings. Overall, the triangulation of reports from both partners, as well as with the qualitative data, enhances the validity and strength of our findings.

Finally, while we are confident in our conclusions regarding the multifaceted benefits of participation in the couples curriculum among our study participants, it is important to note that the hypothesised spill-over benefits to the larger community did not occur ${ }^{13}$ and that the findings of the benefits to these couples may not be generalisable to other settings. In this regard, the lessons learnt from our detailed process evaluation ${ }^{21}$ will help the field to gauge which aspects of the overall Indashyikirwa programme can best be scaled up and adapted to other settings.

\section{CONCLUSION}

This study demonstrates that the Indashyikirwa couples training curriculum was effective at reducing IPV among married and cohabitating male-female couples in rural Rwanda. In addition to reducing IPV in the intervention versus control arm, the programme showed numerous benefits in reduced conflict, improved conflict management, improved mental and physical health, improved economic status and reduced exposure of children to violence. This programme demonstrates that intervention with couples in the Global South can be both safe and beneficial, especially within the context of a supportive intervention, highly trained facilitators and strong referral networks. ${ }^{14}$ Scale-up of such programming and adaption to other settings should be considered, although it will require careful attention to maintaining consistent quality in implementation and should be accompanied by careful process evaluation. The data emphasise how women's economic empowerment combined with interventions supporting relationships skills, and equipping couples to jointly identify and manage triggers of IPV and conflict, can bring significant changes at the household level that are mutually reinforcing.

Acknowledgements We wish to acknowledge the input and support from the implementing partners: CARE International Rwanda, RWARMEC and RWN, as well as the Indashyikirwa participants who were willing to share their experiences. We acknowledge the staff at Laterite Ltd for excellence in fieldwork and data collection. We also wish to acknowledge MIGEPROF for coordinating the Indashyikirwa programme advisory committee. We would like to acknowledge the Lyndsay McLean as early coinvestigator of the impact evaluation. We also acknowledge Robyn Yaker who led the design and facilitator training of the Indashyikirwa couples' curriculum.

Contributors $\mathrm{KD}$ codesigned the study with $\mathrm{LH}$, led the quantitative fieldwork, led the statistical analysis and led the first draft of the manuscript. ES contributed to study design, led the qualitative fieldwork, led the literature review, contributed to interpretation of the findings and cowrote the manuscript. SC participated in data management and statistical analysis and contributed to interpretation of the findings and cowrote the manuscript. LH codesigned the study with KD, supported quantitative and qualitative fieldwork, participated in statistical analysis and interpretation of the findings and cowrote the manuscript. All authors contributed to drafting and revising the manuscript. All authors read and approved the final manuscript.

Funding This work was conducted as part of What Works To Prevent Violence? A Global Programme on Violence Against Women and Girls (VAWG) funded by the UK Government's Department for International Development (DFID). However, the views expressed do not necessarily reflect the department's official policies and the funders had no role in study design; collection, management, analysis and interpretation of data; writing of the report; or the decision to submit the paper for publication. Funding was managed by the South African Medical Research Council.

Competing interests None declared.

Patient and public involvement Patients and/or the public were involved in the design, or conduct, or reporting or dissemination plans of this research. Refer to the Methods section for further details.

\section{Patient consent for publication Not required}

Ethics approval Ethical approval was obtained from the Rwandan National Ethics Committee (340/RNEC/2015) and the South Africa Medical Research Council Ethics Committee (EC033-10/2015). A required research permit was obtained from the National Institute of Statistics Rwanda (0738/2015/10/NISR).

Provenance and peer review Not commissioned; externally peer reviewed.

Data availability statement De-identified individual participant data are available from the corresponding author, but may require permission from the Rwandan Ministry of Gender and Family Promotion (MIGEPROF) before transfer. Data cannot be shared publicly because of the need to ensure that all use complies with the research permit issued by the National Institute of Statistics Rwanda and is approved by the Rwandan Ministry of Gender and Family Promotion (MIGEPROF).

Open access This is an open access article distributed in accordance with the Creative Commons Attribution Non Commercial (CC BY-NC 4.0) license, which permits others to distribute, remix, adapt, build upon this work non-commercially, and license their derivative works on different terms, provided the original work is properly cited, appropriate credit is given, any changes made indicated, and the use is non-commercial. See: http://creativecommons.org/licenses/by-nc/4.0/.

\section{ORCID iD}

Kristin Dunkle http://orcid.org/0000-0003-3071-5544

\section{REFERENCES}

1 Devries KM, Mak JYT, García-Moreno C, et al. Global health. the global prevalence of intimate partner violence against women. Science 2013;340:1527-8.

2 Ellsberg M, Jansen HAFM, Heise L, et al. Intimate partner violence and women's physical and mental health in the who multi-country study on women's health and domestic violence: an observational study. Lancet 2008;371:1165-72.

3 Goodwin SC, Meisel, J D. Violence against women: the role of welfare reform Washington DC: US National Institute of justice 2003.

4 Roberts AL, Gilman SE, Fitzmaurice G, et al. Witness of intimate partner violence in childhood and perpetration of intimate partner violence in adulthood. Epidemiology 2010;21:809-18.

5 Kerr-Wilson A, Gibbs A, McAslan Fraser E, et al. What works to prevent violence against women and girls? A rigorous global evidence review of interventions to prevent violence against women and girls. Pretoria, South Africa: What Works to Prevent Violence Against Women and Girls, 2019.

6 Pronyk PM, Hargreaves JR, Kim JC, et al. Effect of a structural intervention for the prevention of intimate-partner violence and HIV in rural South Africa: a cluster randomised trial. Lancet 2006;368:1973-83.

7 Abramsky T, Devries K, Kiss L, et al. Findings from the Sasa! study: a cluster randomized controlled trial to assess the impact of a community mobilization intervention to prevent violence against women and reduce HIV risk in Kampala, Uganda. BMC Med 2014; $12: 122$

8 Armenti NA, Babcock JC. Conjoint treatment for intimate partner violence: a systematic review and implications. Couple and Family Psychology: Research and Practice 2016;5:109-23.

9 Stern E, Gibbs A, Willan S, et al. When you talk to someone in a bad way or always put her under pressure, it is actually worse than beating her': conceptions and experiences of emotional intimate partner violence in Rwanda and South Africa. PLoS One 2019;14:e0225121. 
10 Todahl J, Linville D, Tuttle Shamblin AF, et al. Client narratives about experiences with a multicouple treatment program for intimate partner violence. J Marital Fam Ther 2012;38:150-67.

11 Ellsberg M, Arango DJ, Morton M, et al. Prevention of violence against women and girls: what does the evidence say? Lancet 2015;385:1555-66.

12 Stern E, McGhee S, Ferguson G, et al. A comparative case study of couples programming to support relationship quality in Nepal and Rwanda. J Soc Pers Relat 2020;37:393-413.

13 Chatterji S, Stern E, Dunkle K, et al. Community activism as a strategy to reduce intimate partner violence (IPV) in rural Rwanda: results of a community randomised trial. J Glob Health 2020;10:010406.

14 Stern E, Carlson K. Indashyikirwa Women's Safe Spaces: Informal Response for Survivors of IPV within a Rwandan Prevention Programme. Soc Sci 2019;8:76.

15 Slegh H, Barker G, Kimonyo A, et al. 'I can do women's work': reflections on engaging men as allies in women's economic empowerment in Rwanda. Gender \& Development 2013;21:15-30.

16 Abramsky T, Devries K, Kiss L, et al. A community mobilisation intervention to prevent violence against women and reduce HIV/ AIDS risk in Kampala, Uganda (the Sasa! study): study protocol for a cluster randomised controlled trial. Trials 2012;13:96.

17 Abramsky T, Devries KM, Michau L, et al. The impact of Sasa!, a community mobilisation intervention, on women's experiences of intimate partner violence: secondary findings from a cluster randomised trial in Kampala, Uganda. J Epidemiol Community Health 2016;70:818-25.

18 Kyegombe N, Abramsky T, Devries KM, et al. The impact of Sasa! a community mobilization intervention, on reported HIV-related risk behaviours and relationship dynamics in Kampala, Uganda. $J$ Int AIDS Soc 2014:17:19232.

19 National Institute of Statistics of Rwanda - NISR, Ministry of Health $\mathrm{MOH} /$ Rwanda, International I. Demographic and health survey 2010. Kigali Rwanda, 2012.

20 Kyegombe N, Starmann E, Devries KM, et al. 'SASA! is the medicine that treats violence'. qualitative findings on how a community mobilisation intervention to prevent violence against women created change in Kampala, Uganda. Glob Health Action 2014;7:25082.

21 Stern E, Martins S, Stefanik L, et al. Lessons learned from implementing Indashyikirwa in Rwanda- an adaptation of the Sasa! approach to prevent and respond to intimate partner violence. Eval Program Plann 2018;71:58-67.

22 World Health Organization. WHO multi-country study on women's health and domestic violence against women. Geneva, Switzerland: World Health Organization, 2005

23 Hemming K, Girling AJ, Sitch AJ, et al. Sample size calculations for cluster randomised controlled trials with a fixed number of clusters. BMC Med Res Methodol 2011;11:102.

24 Singer JD, Willett JB, Willett JB. Applied longitudinal data analysis: modeling change and event occurrence: Oxford university press 2003.

25 Stern E, Nyiratunga R. A process review of the Indashyikirwa couples curriculum to prevent intimate partner violence and support healthy, equitable relationships in Rwanda. Soc Sci 2017;6:63.

26 Stern E, Niyibizi LL. Shifting perceptions of consequences of IPV among beneficiaries of Indashyikirwa: an IPV prevention program in Rwanda. J Interpers Violence 2018;33:1778-804.

27 McLean L, Heise LL, Stern EA. Shifting and transforming genderinequitable beliefs, behaviours and norms in intimate partnerships: the Indashyikirwa couples programme in Rwanda. Cult Health Sex 2019:1-18.
28 Stern E, Heise L. Sexual coercion, consent and negotiation: processes of change amongst couples participating in the Indashyikirwa programme in Rwanda. Cult Health Sex 2019;21:867-82.

29 Doyle K, Levtov RG, Barker G, et al. Gender-transformative Bandebereho couples' intervention to promote male engagement in reproductive and maternal health and violence prevention in Rwanda: findings from a randomized controlled trial. PLoS One 2018;13:e0192756.

30 Jewkes R, Nduna M, Levin J, et al. Impact of stepping stones on incidence of HIV and HSV-2 and sexual behaviour in rural South Africa: cluster randomised controlled trial. BMJ 2008:337:a506.

31 Lewis MA, McBride CM, Pollak KI, et al. Understanding health behavior change among couples: an interdependence and communal coping approach. Soc Sci Med 2006;62:1369-80.

32 Conroy AA, McGrath N, van Rooyen $\mathrm{H}$, et al. Power and the association with relationship quality in South African couples: implications for HIV/AIDS interventions. Soc Sci Med 2016;153:1-11

33 Jewkes RK, Dunkle K, Nduna M, et al. Intimate partner violence, relationship power inequity, and incidence of HIV infection in young women in South Africa: a cohort study. Lancet 2010;376:41-8.

34 Stern E, Heise L, McLean L. The doing and undoing of male household decision-making and economic authority in Rwanda and its implications for gender transformative programming. Cult Health Sex 2018;20:976-91.

35 Lang AJ, Stein MB. An abbreviated PTSD checklist for use as a screening instrument in primary care. Behav Res Ther 2005:43:585-94.

36 Lang AJ, Wilkins K, Roy-Byrne PP, et al. Abbreviated PTSD checklist (PCL) as a guide to clinical response. Gen Hosp Psychiatry 2012;34:332-8

37 Stern E, Willan S, Gibbs A, et al. Pathways of change: qualitative evaluations of IPV prevention programmes in Ghana, Rwanda, Tajikistan and South Africa. Culture, Health \& Sexuality.

38 Basile KC. Histories of violent victimization among women who reported unwanted sex in marriages and intimate relationships: findings from a qualitative study. Violence Against Women 2008;14:29-52.

39 Macalino GE, Celentano DD, Latkin C, et al. Risk behaviors by audio computer-assisted self-interviews among HIV-seropositive and HIVseronegative injection drug users. AIDS Educ Prev 2002;14:367-78.

40 Fenton KA, Johnson AM, McManus S, et al. Measuring sexual behaviour: methodological challenges in survey research. Sex Transm Infect 2001:77:84-92.

41 Rathod SD, Minnis AM, Subbiah K, et al. ACASI and face-to-face interviews yield inconsistent estimates of domestic violence among women in India: the Samata health study 2005-2009. J Interpers Violence 2011;26:2437-56.

42 Andresen EM, Malmgren JA, Carter WB, et al. Screening for depression in well older adults: evaluation of a short form of the CES-D (center for epidemiologic studies depression scale). Am J Prev Med 1994:10:77-84.

43 Bush K, Kivlahan DR, McDonell MB, et al. The audit alcohol consumption questions (AUDIT-C): an effective brief screening test for problem drinking. ambulatory care quality improvement project (ACQUIP). alcohol use disorders identification test. Arch Intern Med 1998;158:1789-95.

44 Bradley KA, Bush KR, Epler AJ, et al. Two brief alcohol-screening tests from the alcohol use disorders identification test (audit): validation in a female Veterans Affairs patient population. Arch Intern Med 2003;163:821-9. 